\title{
Forward Osmosis Desalination of Oil and Gas Wastewater: Impacts of Membrane Selection and Operating Conditions on Process Performance
}

\author{
Bryan D. Coday ${ }^{1}$, Nohemi Almaraz ${ }^{1}$, and Tzahi Y. Cath ${ }^{1, *}$ \\ ${ }^{1}$ Colorado School of Mines, Golden, CO, USA \\ * Corresponding author: \\ Address: 1500 Illinois St., Golden, CO 80401, USA \\ Telephone: +1-303-273-3402 \\ E-mail address: tcath@mines.edu
}

A manuscript prepared for possible publication in the

Journal of Membrane Science

January 2015 


\section{Abstract}

Water treatment technologies that employ sustainable driving forces for treatment of high ionic strength, complex feed streams and have the capacity to separate a broad range of contaminants are needed for economical treatment of flowback and produced waters in the oil and gas industry. This is especially true given the surging interest in treatment of oil and gas wastewaters for reuse in hydraulic fracturing or discharge to the environment in lieu of deep well injection. Forward osmosis is a robust membrane separation technology that can provide superior rejection of a broad range of feed stream contaminants and dissolved ions, thus providing a brine stream suitable for reuse in hydraulic fracturing or excellent pretreatment for downstream desalination processes. In this work, the impacts of membrane selection (asymmetric cellulose triacetate versus polyamide thin-film composite) and system operating conditions on the performance of FO membranes for desalination of produced water for the Niobrara shale formation are investigated. Specifically, water flux, contaminant rejection, membrane fouling, and chemical cleaning were evaluated using a combination of standard methodology and operating conditions analogous to those employed when operating industrial spiral wound FO membrane modules. Membrane autopsy was conducted to determine what effect(s) membrane physiochemical properties might have on system performance and to interpret the potential molecular level interactions occurring near the membrane-feed stream interface. Results from this study indicate that FO can achieve high rejection of organic and inorganic contaminants, membrane fouling can be mitigated with chemical cleaning, and long-term FO system performance might be better controlled with optimized hydrodynamic conditions near the membrane surface (i.e., feed flow velocity, module design, membrane packing) and not by membrane selection.

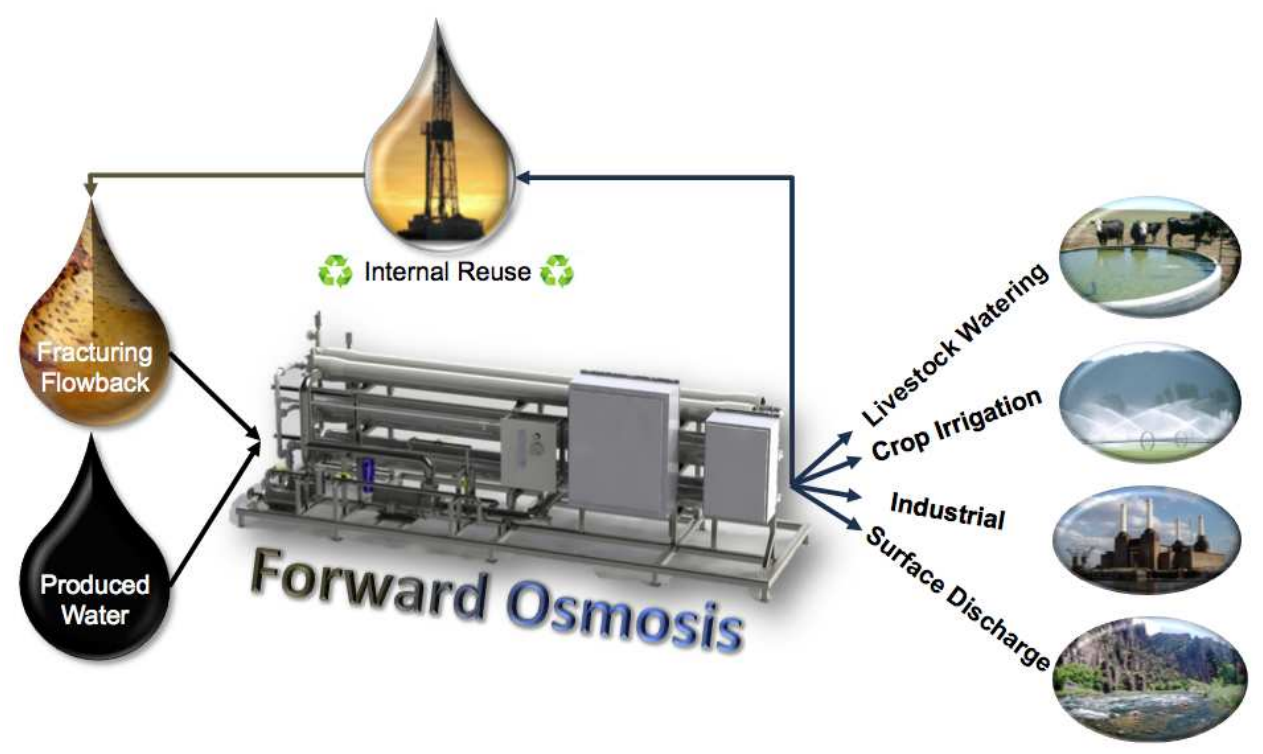

Keywords: Forward osmosis, Produced water, Fracturing flowback, Wastewater treatment, Membrane Fouling, Solute Rejection, Cellulose triacetate, Thin-film composite 


\section{Introduction}

\subsection{Hydraulic fracturing flowback and produced water in unconventional oil and gas}

Hydraulic fracturing flowback and produced water are complex industrial waste streams resulting from the exploration and development of unconventional oil and gas (O\&G) resources. During hydraulic fracturing a water-based slurry, typically in the range of 4 million gallons, is injected into the oil or gas well under extremely high pressures [1-3]. This process fractures the subsurface O\&G formation, effectively increasing the permeability of the reservoir and enhancing recovery of hydrocarbons. The hydraulic fracturing process occurs after a well has been drilled and can be repeated several times throughout the service life of the well. After the fracturing process has been completed, a portion of the fracturing fluids are recovered from the well for up to a month, generating an industrial waste stream (commonly termed "flowback water") consisting of water, proppants (i.e., silica, graded sand or ceramic materials), chemical additives, and a variety of subsurface formation minerals and organic compounds [3-6]. Over time, the fluids recovered from the well transition from flowback water to natural formation water (commonly termed "produced water"). The quality and quantity of produced water extracted from an O\&G formation is spatially and temporally dependent, but typically contains a wide range of total dissolved solids (TDS), hydrocarbons, organic compounds, and dissolved metals $[3,5,6]$.

Historically, most flowback and produced water from unconventional O\&G wells are impounded and then trucked off-site for disposal in Class II injection wells [6-8]. However, the availability of sufficient injection well capacity is a potentially restricting aspect in ongoing exploration and development of $O \& G$ fields [1]. Although the quantity of Class II injection wells is likely to increase in most basins as they mature, the development of new disposal facilities can be complex, requiring significant capital investment and time, and overcoming regulatory barriers. Furthermore, the geology in certain regions such as Pennsylvania (Marcellus shale play) is not conducive for deep well injection, limiting the options for flowback and produced water disposal $[1,6,9]$. This is especially important considering the potential for seismic activity resulting from the operation of disposal wells. While discharge and dilution of flowback and produced water into municipal wastewater treatment facilities has been attempted, it has been shown to be an inadequate management solution $[1,8]$. The TDS concentrations that can be accepted by municipal wastewater facilities are limited by regulations, especially those controlling discharge to sensitive aqueous environments. The organic loading of flowback and produced water can also fluctuate significantly, potentially upsetting biological treatment processes and impacting wastewater effluent quality. Therefore, one of the most promising management strategies for these industrial wastewaters is treatment and local reuse for subsequent hydraulic fracturing processes [10, 11].

\subsection{On-site water reuse}

Local and regional reuse of flowback and produced waters can significantly limit the volumes of wastewater sent for deep well injection, thus reducing the environmental impacts and risks associated 
with regional water trucking [12]. On-site water reuse can also be economically favorable by minimizing exploration expenses through reduced trucking frequency, fresh water procurement for hydraulic fracturing, and wastewater management at deep well injection facilities [13]. However, there are several limiting factors associated with flowback and produced water quality that should be addressed before onsite reuse is considered. Of significant importance is the stability of the chemical constituents and fracturing gels when mixed with reclaimed flowback and produced waters for subsequent hydraulic fracturing operations [1, 13, 14]. Inorganic precipitates are also of significant concern, specifically precipitation of carbonate and sulfate species in the presence of a variety of dissolved ions (e.g., barium, strontium, and calcium) [1, 13-15]. While chemical companies and oil field service providers are continually developing chemical additives that are compatible with high TDS, low quality waters [13, 16], the opportunity to generate reuse water of varying qualities is of growing interest. This is especially true for companies interested in both water reuse for hydraulic fracturing and treating and discharging flowback or produced waters to the environment in lieu of deep well injection. A wide variety of technologies can be used for onsite treatment and desalination of flowback and produced waters, including distillation and pressure driven membrane processes [1, 2]; however, these technologies are susceptible to premature failure if the feed water is not of suitable quality - traditionally, these wastewaters require multiple upstream pretreatment processes. A multi-step treatment process might limit the efficiency of on-site water treatment, reduce system mobility and modularity, and ultimately become economically unfavorable. Therefore, technologies that employ sustainable driving forces for treatment of high TDS, impaired feed streams and have the capacity to separate a broad range of contaminants are needed for economical treatment of flowback and produced water.

\subsection{Forward osmosis for treatment of fracturing flowback and produced water}

Forward osmosis (FO) is a robust membrane separation technology that can provide superior rejection of a broad range of feed stream contaminants and TDS, while operating with minimal hydraulic pressure [17]. FO utilizes the chemical potential between a highly concentrated draw solution (e.g., $\mathrm{NaCl}$ ) and a lower salinity feed solution to drive the permeation of water across a semipermeable membrane. The FO process can achieve solute rejection similar to reverse osmosis $(\mathrm{RO})$, while traditionally avoiding the need for significant upstream pretreatment to mitigate irreversible fouling and premature membrane failure. The FO process has been proposed as a suitable, on-site treatment process for management of flowback and produced waters [2, 18]; however, few studies to date have investigated the performance of FO membranes for treatment of these complex feed streams [19-23]. Of those studies, only three were from academia [19, 21, 23], while the remaining were pilot scale evaluations from industry [20, 22]. Hickenbottom et al. [23] first investigated treatment of O\&G pit water with a cellulose triacetate (CTA) membrane from Hydration Technology Innovations (Albany, OR (HTI)). Since, Yun et al. [19] and Li et al. [21] have investigated treatment of flowback and produced waters using FO; however, Yun et al. employed synthetic feed solutions, while Li et al. employed a flowback feed stream from O\&G exploration 
that had been chemically and physically pretreated prior to the FO process. Furthermore, both studies used only the CTA membrane manufactured by $\mathrm{HTI}$ and employed operating conditions that might misrepresent membrane performance experienced in full-scale FO applications.

\subsection{Objectives}

The main objective of this study was to investigate the impacts of membrane selection and operating conditions on the performance of FO membranes for desalination of produced water. Specifically, water flux, contaminant rejection, and membrane fouling were evaluated using a combination of standard methodology and system operating conditions analogous to those used in the operation of industrial spiral wound FO membranes. A series of bench-scale experiments were conducted on three polymeric membranes to elucidate the role of initial permeate flux, cross-flow velocity, feed stream turbulence enhancement, and transmembrane hydraulic pressure on fouling of FO membranes operated under extreme feed stream chemistries. Membrane autopsy was also conducted to determine the influence of membrane physiochemical properties on system performance and to interpret the potential molecular level interactions occurring near the membrane-solution interface. The results of this study can be used to determine the applicability of FO operated with spiral wound modules for treatment of complex O\&G waste streams without pretreatment.

\section{Materials and methods}

\subsection{FO membranes}

Three flat sheet FO membranes were tested. The first membrane was an asymmetric cellulose triacetate (CTA) membrane from Hydration Technology Innovations (HTI) (Albany, OR). This membrane is commercially available and is thoroughly referenced in the literature [17, 24-26]. The other two membranes are thin film composite (TFC) polyamide-based membranes also manufactured by $\mathrm{HTI}$. The first TFC membrane is a derivative of a TFC membrane that was studied in a previous investigation (designated TFC1 in this study) [27]. The second TFC membrane is not commercially available and has not been previously described in the literature. The active layer of this membrane was surface-modified by $\mathrm{HTI}$ and was designated TFC2 in this study. All experiments were conducted with the membrane active layer facing the feed solution (FS). The water and solute permeability coefficients (A and B, respectively) and structural parameter (S) of each membrane were determined using methodology presented by Tiraferri et al. [28].

Membrane coupons were soaked in deionized water for $24 \mathrm{hrs}$ prior to installation in the test cell. No additional membrane wetting techniques were employed. To maintain high quality assurance and control, membrane integrity tests were conducted prior to all experiments. Fouled membranes were removed at the end of each set of experiments and new coupons were installed to minimize performance bias (i.e., water flux, contaminant rejection, fouling propensity) in subsequent experiments. 


\subsection{Membrane characterization}

\subsubsection{Surface roughness and microscopy imaging}

Atomic force microscopy (AFM) experiments were performed using an Autoprobe CP atomic force microscope (Park Scientific Instruments, Sunnyvale, CA) coupled with silicon nitride cantilevers and pyramidal tips (VEECO Instruments, Inc., Fremont, CA). Membrane surface morphology was imaged on dry coupons in tapping mode. The roughness of each membrane is reported as average roughness $\left(R_{a}\right)$ and root mean square roughness $\left(R_{\mathrm{q}}\right)$.

Membrane fouling was characterized using environmental scanning electron microscopy (ESEM) Quanta 600 (FEl Company, Hillsboro, OR) coupled with energy dispersive x-ray spectroscopy (EDS). Surface and cross-sectional imaging was conducted on each sample analyzed. To view the membrane cross-section, coupons were submerged in liquid nitrogen and cut with a razor blade. Prior to ESEM imaging, samples were sputtered with gold to avoid charging of the non-conductive membrane surface.

\subsubsection{Surface charge: streaming potential measurements}

Streaming potential analyses were conducted using an electrokinetic analyzer (SurPASS, Anton Paar $\mathrm{GmbH}$, Austria) equipped with an adjustable gap cell which holds two membrane coupons $20 \mathrm{~mm} \times 10$ $\mathrm{mm}$ in size. Streaming potential measurements were conducted at room temperature using $2 \mathrm{mM} \mathrm{KCl}$ electrolyte solution, a target ramp pressure of $300 \mathrm{mbar}$, and gap of $116 \pm 2 \mu \mathrm{m}$ between the membrane coupons. The $\mathrm{pH}$ of the electrolyte was adjusted using $0.1 \mathrm{M}$ hydrochloric acid or $0.1 \mathrm{M}$ potassium hydroxide ( $\mathrm{pH} 3$ to 10 for TFC and $\mathrm{pH} 4$ to 8 for CTA). Streaming potential was measured 4 times at each $\mathrm{pH}$ and then averaged to calculate the zeta $(\zeta)$ potential using the Helmholtz-Smoluchowski equation [29]

$\zeta=\frac{d U_{s t r}}{d p} \cdot \frac{\eta}{\varepsilon_{r} \cdot \varepsilon_{0}} \cdot k$

where $d U_{s t r} / d p$ is the streaming potential coefficient, $\varepsilon_{r}$ is the relative permittivity of the electrolyte, $\varepsilon_{0}$ is the vacuum permittivity, $\eta$ is the electrolyte viscosity, and $k$ is the bulk electrolyte conductivity. The derivation of the Helmholtz-Smoluchowski equation has been presented and discussed in greater detail in previous membrane studies [29, 30].

\subsubsection{Surface energetics: contact angle measurements}

Surface energy parameters of each virgin membrane active layer were estimated using a goniometer (Rame-Hart Inc., Mountain Lakes, NJ). Captive bubble contact angle $\left(\theta_{c}\right)$ measurements were conducted under ambient conditions $\left(\sim^{\circ}{ }^{\circ} \mathrm{C}\right)$ with de ionized water, glycerol ( $\left.\geq 99 \%\right)$ (Sigma-Aldrich, St. Louis, MO), and diiodomethane ( $\geq 99 \%$ ) (Sigma-Aldrich). Steady state contact angle was measured after $1 \mathrm{~min}$ of interfacial interaction between the hydrated membrane surface and a $10 \mu \mathrm{L}$ air bubble. No less than ten contact angle measurements were recorded on each membrane coupon. Averaged contact angle measurements were used to determine the surface energetics of each membrane using the 
Lifshitz-van der Waals acid-base approach following similar procedures outlined in the literature [31, 32]. Estimates of the long-range surface forces (non-polar) and short-range acid-base (polar) forces for each membrane were determined through the extended Young equation [31-34]

$\left.\left(1+\cos \theta_{c}\right) \gamma_{l}^{T O T}=2\left(\sqrt{\gamma_{s}^{L W} \gamma_{l}^{L W}}+\sqrt{\gamma_{s}^{+} \gamma_{l}^{-}}+\sqrt{\gamma_{s}^{+} \gamma_{l}^{-}}\right)\right)$

where $\gamma^{\text {TOT }}$ is the total surface tension, $\gamma^{\mathrm{LW}}$ is the Lifshitz-van der Waals parameter, $\gamma^{+}$is the electron acceptor parameter, and $\gamma$ is the electron donor parameter. The subscripts $/$ and $s$ represent the liquid and solid membrane surface, respectively. Surface tension properties for the three probe liquids were obtained from the literature [35]. The acid-base component and the total surface tension of each membrane's surface were determined using Eqs. 3 and 4, respectively

$\gamma^{A B}=2 \sqrt{\gamma^{+} \gamma^{-}}$

$\gamma^{T O T}=\gamma^{L W}+\gamma^{A B}$

The interfacial free energy of adhesion per unit area gives an indication of each membrane's hydrophilicity when submerged in an aqueous solution and can be calculated from the $\gamma^{+}, \bar{\gamma}$, and $\gamma^{\mathrm{LW}}$ surface energy components. The total interfacial free energy for each membrane active layer is given by $[31,32,35]$

$\Delta G_{132}^{T O T}=\Delta G_{132}^{A B}+\Delta G_{132}^{L W}$

$\Delta G_{132}^{A B}=2 \sqrt{\gamma_{3}^{+}}\left(\sqrt{\gamma_{1}^{-}}+\sqrt{\gamma_{2}^{-}}-\sqrt{\gamma_{3}^{-}}\right)+2 \sqrt{\gamma_{3}^{-}}\left(\sqrt{\gamma_{1}^{+}}+\sqrt{\gamma_{2}^{+}}-\sqrt{\gamma_{3}^{+}}\right)-2 \sqrt{\gamma_{1}^{+} \gamma_{2}^{-}}-2 \sqrt{\gamma_{1}^{-} \gamma_{2}^{+}}$,

$\Delta G_{132}^{L W}=2\left(\sqrt{\gamma_{3}^{L W}}-\sqrt{\gamma_{1}^{L W}}\right)\left(\sqrt{\gamma_{2}^{L W+}}-\sqrt{\gamma_{3}^{L W}}\right)$.

Surfaces 1 and 2 are assumed as identical membrane active layers; therefore, $\Delta G_{132}^{T O T}$ (Eq. 5) can be simplified to $\Delta G_{131}^{T O T}$, or $\Delta G_{S W S}^{T O T}$, where positive and negative values are indicative of a hydrophilic and hydrophobic membrane surface, respectively [31, 32, 36].

\subsubsection{Surface chemistry: ATR-FTIR spectroscopy}

Attenuated Total Reflectance Fourier Transform Infrared Spectroscopy (ATR-FTIR) analysis was conducted in order to characterize the surface chemistry of the membrane coupons. The goal of ATRFTIR measurements was not to identify individual functional groups of each membrane surface, but to ascertain possible changes to the polymeric surface of the FO membranes after exposure to produced 
water. Transmittance spectra were measured using a Nicolet IS50 FTIR spectrometer (Thermo Scientific, Madison, WI). The spectrometer was equipped with a built-in ATR (diamond crystal) accessory coupled with a DTGS detector and $\mathrm{KBr}$ beam splitter. A gripper device maintained contact between the membrane active layer and the ATR crystal. A background spectrum was measured prior to each membrane analysis and was subtracted from the membrane spectrum using the Omnic analysis software (Thermo Scientific, Madison, WI). Each spectrum was measured using 10 scans at resolution $4\left(0.482 \mathrm{~cm}^{-1}\right)$.

\subsection{Solution chemistries}

The concentrations of major constituents measured in the feed during this study are summarized in Table 1. The feed was a comingled industrial wastewater consisting of produced water influenced by hydraulic fracturing flowback (termed produced water in this study) originating from the Niobrara Shale formation. The produced water was obtained from an O\&G service provider in the Denver-Julesburg basin, located northeast of Denver, CO. To minimize chemical variability in the feed, $210 \mathrm{~L}$ of flowback were collected in a single sampling event and stored in a climate-controlled room for the duration of the study. The DS was prepared using ACS grade NaCl (Fisher Scientific, Fair Lawn, NJ).

Table 1. Average concentrations of major constituents measured in the produced water.

\begin{tabular}{lr}
\hline Constituent & $\mathrm{mg} / \mathrm{L}$ \\
\hline $\mathrm{pH}$ & 6.9 \\
Total suspended solids & 314 \\
Total organic carbon & 95 \\
Dissolved organic carbon & 70 \\
Total nitrogen & 38 \\
Total carbohydrates (guar) & 50 \\
Alkalinity (as CaCO3) & 570 \\
Hardness (as CaCO3) & 555 \\
Total dissolved solids (TDS) ${ }^{\mathrm{a}}$ & 24,646 \\
Fluoride & 37 \\
Chloride & 14,694 \\
Nitrate & 0 \\
Sulfate & 0 \\
Bromide & 88 \\
Barium & 8 \\
Calcium & 1121 \\
Magnesium & 121 \\
Lithium & 6 \\
Potassium & 127 \\
Iron & 79 \\
Manganese & 2 \\
Sodium & 8209 \\
Phosphorous & 5 \\
Silicon & 87 \\
Strontium & 60 \\
Zinc & 1 \\
Nickel & 2 \\
\hline a Cations = 431.4 meq/L; $\Sigma$ Anions = -417.5 meq/L &
\end{tabular}


The cleaning efficiencies of KL7330 (King Lee Technologies, San Diego, CA) and ethylenediaminetetraacetic acid (EDTA) (Avantor, Central Valley, PA) were investigated in select experiments. KL7330 is a powder cleaner that targets oils, greases, and organic particulates at neutral solution $\mathrm{pH}$, making it suitable for CTA and TFC membrane applications. EDTA was chosen because of its chelating properties, especially for cleaning polymeric membranes fouled by divalent cation-organic compound complexations; the EDTA solution $\mathrm{pH}$ was adjusted to $\mathrm{pH} 11$ and $\mathrm{pH} 7.9$ for the TFC and CTA membranes, respectively. The solution strength of both chemicals was $11,000 \mathrm{mg} / \mathrm{L}$ following the manufacturer's recommendations.

\subsection{Bench-scale FO system}

The bench-scale system used in this study was similar to that described in previous publications [27]; a schematic of the system is provided in Fig. S1 of the Supporting Materials. A custom-made membrane test cell with symmetrical flow channels $(76 \times 255 \mathrm{~mm}$ ) was employed. Feed and DS flow channel depth was controlled independently using nitrile rubber gaskets in order to incorporate turbulence enhancing spacers. Commercially available tricot and chevron spacers [26] were chosen to mimic the hydrodynamic conditions inside spiral wound membrane elements and were installed in the DS and feed channels, respectively, during select experiments. LabVIEW data acquisition software (National Instruments, Austin, TX) and UE9-Pro DAQ systems (LabJack, Lakewood, CO) were used to control experimental test conditions (i.e., solution temperature, feed volume, and DS concentration) and to collect experimental data (i.e., permeate volume, DS and feed conductivity).

\subsection{Experimental procedures}

All tests were conducted with $1 \mathrm{~L}$ (initial volume) DS $(1 \mathrm{M} \mathrm{NaCl})$ and $3 \mathrm{~L}$ of produced water $\mathrm{FS}$ at constant temperature $(20 \pm 0.5 \mathrm{C})$. The feed volume and DS concentration were held constant by intermittent dosing of deionized water into the feed tank and concentrated $\mathrm{NaCl}$ stock solution $(300 \mathrm{~g} / \mathrm{L})$ into the DS tank. Batch experiments with hydrodynamic conditions similar to recently published standard methodology and conditions analogous to those in spiral wound FO elements were performed during four separate test sets (Table 2).

For each set of experiments, a new membrane was installed in the membrane cell and tested with a produced water feed for $24 \mathrm{hrs}$. After $24 \mathrm{hrs}$, the system was stopped and the draw solution was replaced with deionized water, leaving the produced water in the feed hydraulic system in order to induce an osmotic backwash. In osmotic backwashing the direction of water permeation is reversed, thus removing foulants that have accumulated at the surface of the membrane [37, 38]. The fouled membrane was osmotically backwashed for $30 \mathrm{~min}$ at $0.2 \mathrm{~m} / \mathrm{s}$ cross-flow velocity in both flow channels and 0.07 bar transmembrane pressure (TMP) in favor of the feed. Following osmotic backwashing, the feed and DS were replaced with new produced water and $\mathrm{NaCl}$ brine and the membrane fouling test was resumed for an additional $24 \mathrm{hrs}$. Fouled membranes were osmotically backwashed once more and removed from the 
test cell for autopsy; half of the coupon was stored wet at $5^{\circ} \mathrm{C}$, while the other half was dried in a desiccator.

Table 2. Summary of bench-scale operating conditions.

\begin{tabular}{clll}
\hline Test Set & Experimental Condition & Value & Units \\
\hline & Feed cross-flow velocity & 0.20 & $\mathrm{~m} / \mathrm{s}$ \\
A & DS cross-flow velocity & 0.20 & $\mathrm{~m} / \mathrm{s}$ \\
& Transmembrane pressure & $<0.07(1)$ & $\mathrm{bar}(\mathrm{psi})$ \\
& DS spacer/feed spacer & tricot/NA & $\mathrm{NA}$ \\
\hline \multirow{4}{*}{ B } & Feed cross-flow velocity & 0.20 & $\mathrm{~m} / \mathrm{s}$ \\
& DS cross-flow velocity & 0.20 & $\mathrm{~m} / \mathrm{s}$ \\
& Transmembrane pressure & $<0.07(1)$ & $\mathrm{bar}(\mathrm{psi})$ \\
& DS spacer/feed spacer & tricot/chevron & $\mathrm{NA}$ \\
\hline \multirow{4}{*}{ C } & Feed cross-flow velocity & 0.30 & $\mathrm{~m} / \mathrm{s}$ \\
& DS cross-flow velocity & 0.10 & $\mathrm{~m} / \mathrm{s}$ \\
& Transmembrane pressure & $0.27(4)$ & $\mathrm{bar}(\mathrm{psi})$ \\
& DS spacer/feed spacer & tricot/chevron & $\mathrm{NA}$ \\
\hline \multirow{4}{*}{ D } & Feed cross-flow velocity & 0.30 & $\mathrm{~m} / \mathrm{s}$ \\
& DS cross-flow velocity & 0.10 & $\mathrm{~m} / \mathrm{s}$ \\
& Transmembrane pressure & $2.76(40)$ & $\mathrm{bar}(\mathrm{psi})$ \\
& DS spacer/feed spacer & tricot/chevron & $\mathrm{NA}$ \\
\hline
\end{tabular}

\subsubsection{Baseline membrane performance}

Hydrodynamic conditions similar to recently published standard methodology were used during test set $A$ [27]. This test set was conducted with $0.2 \mathrm{~m} / \mathrm{s}$ cross-flow velocity in both flow channels to minimize TMP across the membrane ( $<0.07$ bar in favor of the feed). No spacer was installed in the feed channel; however, a triple layered tricot spacer was used in the DS channel to provide mechanical support to the membrane and maintain a uniform flow channel. DS spacers were also used in test set $A$ to ensure that changes in membrane performance observed in later test sets were independent of the DS spacer [39]. Results from test set A provided a baseline for comparing disparities in membrane fouling due to differences in membrane surface chemistry and physiochemical properties. The baseline results also served as a benchmark for comparing changes in membrane performance when operating under physical and hydrodynamic conditions similar to those used in spiral wound FO elements.

\subsubsection{Membrane performance under spiral wound operating conditions}

The physical and hydrodynamic operating conditions shown in Table 2 were varied stepwise during test sets $B$ through $D$. The goal was to systematically elucidate membrane performance and fouling under conditions similar to those expected in spiral wound FO elements. Experiments from test set B were conducted with the same cross-flow velocities and TMP as those in test set A; however, a chevron spacer was installed in the feed channel to investigate changes in membrane performance and permeation drag forces in the presence of a feed turbulence enhancer. Experiments in test set $\mathrm{C}$ were conducted with the same spacers as in test set $B$, but the feed cross-flow velocity was increased from $0.2 \mathrm{~m} / \mathrm{s}$ to $0.3 \mathrm{~m} / \mathrm{s}$ and TMP was increased from 0.07 bar to 0.27 bar. Operating conditions in test set $C$ were in agreement with 
those suggested by $\mathrm{HTI}$ in a previous study by Ren et al. [40]. These operating conditions were used to mimic conditions in spiral wound FO elements operated at the outlet of commercial FO pressure vessels. Experiments in test set $D$ were conducted with the same spacers and cross-flow velocities as those in test set $\mathrm{C}$. However, the TMP was increased from 0.27 bar to 2.76 bar to simulate the pressure conditions inside spiral wound elements operated near the inlet of a commercial FO pressure vessel with multiple elements operated in series [27].

\subsubsection{Chemical cleaning}

The efficiency of chemically enhanced osmotic backwashing using KL7330 and EDTA was investigated in an additional set of experiments for an extended duration. Experiments under conditions of test set $D$ were repeated on select membranes and the test duration was increased from $48 \mathrm{hrs}$ to $96 \mathrm{hrs}$. After every $24 \mathrm{hrs}$ of membrane fouling test, the feed and DS were replaced with $1 \mathrm{~L}$ of cleaning solution and $1 \mathrm{~L}$ of deionized water, respectively. The membrane was chemically cleaned for 30 minutes using the same operating conditions employed during osmotic backwashing. After chemical cleaning the feed and DS were replaced with new produced water and $\mathrm{NaCl}$ brine and membrane fouling test was resumed for another $24 \mathrm{hrs}$, after which the cleaning procedure was repeated. After $96 \mathrm{hrs}$ of membrane testing, the coupon was chemically cleaned one more time and removed for autopsy. A new membrane coupon was used when investigating each chemical cleaning solution. It should be noted that membrane cleaning was not optimized in this study. The goal was to establish the effectiveness of traditional osmotic backwashing versus chemical cleaning after FO treatment of produced water to provide insight for future studies.

\subsection{Sampling and analytical methods}

Cation concentrations were analyzed using inductively coupled plasma atomic emission spectroscopy (ICP-AES) (Optima 5400, PerkinElmer, Fremont, CA) according to Standard Method 3120 B. Samples were diluted as necessary to bring sodium concentrations below $500 \mathrm{mg} / \mathrm{L}$ and acidified with $\mathrm{HNO}_{3}$ to below $\mathrm{pH}$ 2. Feed samples were also filtered through a $0.45 \mu \mathrm{m}$ filter to remove suspended solids prior to analysis. Anion concentrations were analyzed using ion chromatography (IC) (ICS-90, Dionex, Sunnyvale, CA) according to Standard Method 4110 B. All samples were diluted as necessary to bring chloride concentrations below $500 \mathrm{mg} / \mathrm{L}$ and feed samples were filtered through a $0.45 \mu \mathrm{m}$ filter to remove suspended solids prior to analysis. A carbon analyzer (Shimadzu TOC-L, Columbia, MD) using the combustion catalytic oxidation method was employed to determine total organic carbon (TOC), dissolved organic carbon (DOC), and total nitrogen (TN) concentrations. 3-D fluorescence spectroscopy analyses were performed on DS samples using a spectrofluorometer (Aqualog, HORIBA Scientific, Edison, NJ). Fluorescence spectroscopy of samples at $20^{\circ} \mathrm{C}$ were analyzed for emission wavelengths between $300 \mathrm{~nm}$ and $600 \mathrm{~nm}$ and excitation wavelengths between $240 \mathrm{~nm}$ and $480 \mathrm{~nm}$. EEMs from each membrane were normalized by DOC concentration ( $2 \mathrm{mg} / \mathrm{L}$ ) to better differentiate between DOC fractions that preferentially permeated through each membrane. 
Feed samples were also analyzed for hardness, alkalinity, and total carbohydrate concentration. Hardness was calculated from analytical results provided by ICP-AES. Alkalinity was determined via titration using sulfuric acid and $\mathrm{HACH}$ method 8203. The anthrone method [41] was used to determine total carbohydrate concentration in the produced water. It was assumed that any concentration of carbohydrates in the feed was attributed to guar gum that is commonly cross-linked and used as a gelling agent during hydraulic fracturing [42].

\section{Results and discussion}

\subsection{Membrane properties}

The measured physiochemical properties of each virgin FO membrane used in this study are summarized in Table 3. CTA exhibited the lowest pure water permeability, solute permeability, and structural parameter of the three membranes tested. TFC1 showed significantly greater pure water permeability than CTA, but also exhibited a much larger solute permeability and structural parameter. Similar to TFC1, the pure water permeability of TFC2 exceeded that of CTA; however, the solute permeability of TFC2 was much lower than that of TFC1 and its structural parameter was nearly identical to that of the CTA membrane.

The surface energy data shows that all three membranes have similarly high Lifshitz-van der Waals components $\left(\gamma^{\mathrm{W}}\right)$ and low electron acceptor components $\left(\gamma^{+}\right)$. The values for $\gamma^{\mathrm{W}}$ and $\gamma^{+}$increased in the order TFC2>CTA>TFC1. For each membrane, the electron donor component $(\bar{\gamma})$ was significantly greater than the electron acceptor component $\left(\dot{\gamma} / \gamma^{+} \geq 15.3\right)$, indicating a high degree of monopolarity for each polymeric surface. These results are consistent with the negative zeta potential values that were calculated for all three membranes. The $\bar{\gamma}$ values are also in agreement with previous studies that characterized a variety of polymeric membranes as having high electron donor monopolarity [31, 33, 34]. The $\bar{\gamma}$ component of TFC1 was the highest of all three membranes, while that of TFC2 was only slightly higher than that of the CTA membrane. These values translate into moderate acid-base components $\left(\gamma^{\mathrm{AB}}\right)$ that are approximately 50\% lower than the respective $\gamma^{\mathrm{LW}}$ component of each membrane and increased in the order TFC2>TFC1>CTA. The magnitude of the $\gamma^{\mathrm{AB}}$ value for each membrane, in relation to its $\gamma^{\mathrm{W}}$ value, was used to calculate the free energy of cohesion ( $\Delta \mathrm{G}_{\mathrm{Sws}}$ ) (Eq. $5 \mathrm{a}$ ) and estimate the membrane's hydrophobicity/hydrophilicity. Values of $\Delta G_{\text {Sws }}$ show that TFC1 is strongly hydrophilic, the surface of TFC2 can be considered slightly hydrophilic, and the surface of CTA can be considered neither hydrophilic nor hydrophobic. In general, the surface roughness of CTA and TFC1 are comparable while that of TFC2 is substantially lower. 


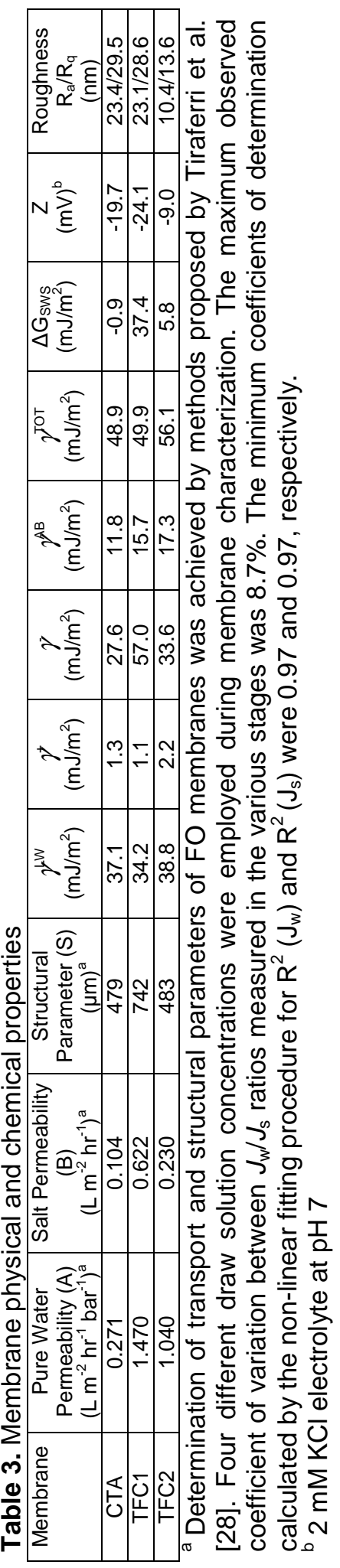




\subsection{FO membrane fouling by O\&G produced water: effects of membrane selection}

Decline in water flux for each of the three membranes during test set $A$ is presented in Fig. 1 as a function of cumulative permeate volume. The water flux $\left(J_{w}\right)$ of each membrane is normalized to its initial water flux $\left(\mathrm{J}_{\mathrm{w} 0}\right)$ recorded at the beginning of the experiment. The normalized water flux shows a distinct, two-stage fouling process separated by the osmotic backwashing. During the initial fouling of the virgin membranes, water flux declines exponentially followed by a gradual transition into near linear flux decline. Constant water flux was not reached before the membranes were osmotically backwashed. Less than $50 \%$ of the original water flux was recovered for the three membranes after osmotic backwashing, indicating potential irreversible fouling. After osmotic backwashing, a near linear flux decline was observed for the three membranes. The overall loss in membrane performance due to fouling during test set $A$ was least for CTA, followed by TFC1 and TFC2.

It is evident that membrane fouling and flux decline occurring before osmotic backwashing is directly proportional to initial water flux and potentially due to permeation drag force of foulants towards the membrane surface. The initial water flux of TFC2 was highest during test set A (7.2 LMH), exceeding that of TFC1 (5.7 LMH) and CTA (3.9 LMH). Note the lower water flux of each membrane due to the high salinity of the feed $(\sim 25,000 \mathrm{mg} / \mathrm{L}$ TDS $(\sim 0.43 \mathrm{M}))$ relative to the $1 \mathrm{M} \mathrm{NaCl} \mathrm{DS}$. Similar findings were presented in recent publications, where the relationship between membrane fouling and initial water flux was investigated [43-45]. Although each membrane exhibits unique physiochemical surface properties (Table 3), a clear relationship between flux decline and membrane hydrophobicity and surface roughness could not be established. This is despite the overwhelming evidence supporting the correlation between membrane surface properties and flux decline under mild fouling conditions in recent publications [45-51]. Increased fouling due to electrostatic charge shielding of the membrane surface has also been previously proposed [52]; however, similar zeta potentials and thus electrostatic attraction-repulsion forces are expected for the three membranes at high ionic strength based on findings presented in our recent study [53]. It is important to note that the water flux of TFC2 was higher than TFC1 during test set A, despite having a slightly lower pure water permeability coefficient (Table 3). Lower than expected TFC1 water flux was attributed to greater internal concentration polarization resulting form its high structural parameter, thus hindering osmotic driving force [44, 54].

During osmotic backwashing, $47 \%$ of the loss in water flux was recovered for CTA, followed by $24 \%$ for TFC1 and 37\% for TFC2. Based on the above results and direct observation of the membrane surface, we infer that the osmotic backwashing removed the majority of the loosely bound foulants near the surface of the complex cake layer, while the foulants sorbed to the membrane surface were not entirely removed. Higher cleaning efficiency for CTA was indeed expected due to lower permeation drag during filtration and the relatively low permeate volume $(1.6 \mathrm{~L})$ compared to the TFC membranes. Flux recovery for TFC1 was much lower than CTA due to greater foulant deposition during filtration and higher permeation drag towards the membrane surface. It is also possible that this higher permeation drag force 
increased the compaction of foulants in the feed stream onto the TFC1 membrane surface, especially into the nano-scale valleys of the rough active layer. Interestingly, flux recovery for TFC2 was only $10 \%$ lower than CTA despite exhibiting the highest permeation drag force and achieving the greatest filtration volume. This flux recovery is attributed to the relatively smooth surface of TFC2, which is over $50 \%$ less rough than TFC1 and CTA. It is well documented that low surface roughness can minimize irreversible fouling and increase the DLVO surface energetics of the membrane surface $[45,46,51,55]$.

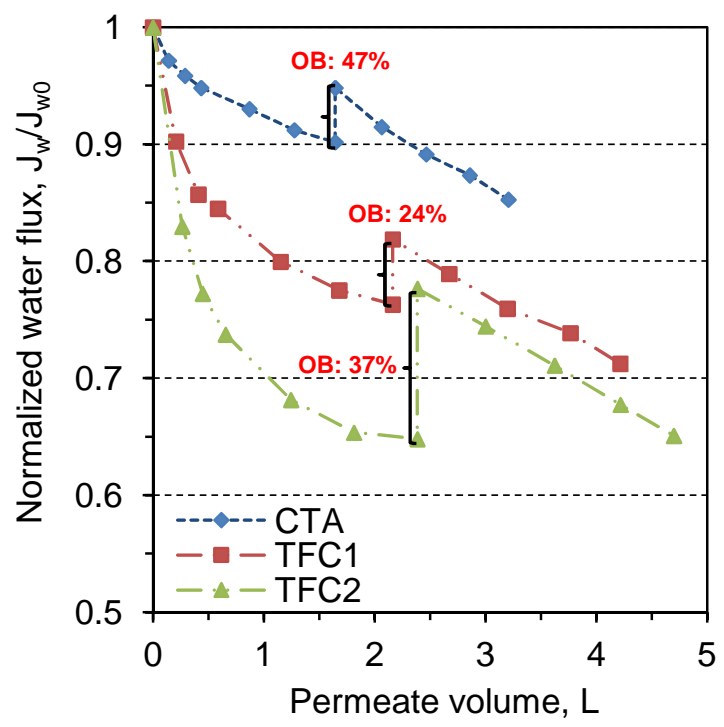

Fig. 1. Normalized water flux for CTA, TFC1, and TFC2 during test set A employing operating conditions described in Table 2. Water flux was normalized to the initial water flux for each membrane, independently. Osmotic backwashing (OB) was conducted after $24 \mathrm{hrs}$ of membrane fouling during each test set. The initial water flux $\left(\mathrm{J}_{\mathrm{wo}}\right)$ was $3.9 \mathrm{LMH}, 5.7 \mathrm{LMH}$, and 7.2 LMH for CTA, TFC1, and TFC2, respectively.

After osmotic backwashing, flux decline was near linear regardless of membrane type. This indicates that long-term fouling and flux decline when treating produced water is dominated by foulant-foulant interactions near the surface of the cake layer. Similar conclusions were drawn in previous studies that investigated organic fouling and cleaning of FO membranes [46, 56].

\subsection{Effects of operating conditions on FO membrane performance}

Normalized water flux as a function of time is shown in Fig. 2 for CTA, TFC1, and TFC2 under the four different operating conditions tested (Table 2). In general, flux decline before osmotic backwashing correlated well with initial water flux. After osmotic backwashing, flux decline appeared to be controlled by foulant-foulant interactions based on the near linear decline in water flux and lack of exponential flux decline observed when employing virgin membranes; however, the rate of flux decline was impacted by changes in hydrodynamic conditions in each test set. Flux recovery after osmotic backwashing was similar for all test sets and there was no clear correlation between changes in hydrodynamic test conditions and osmotic backwashing cleaning efficiency. 

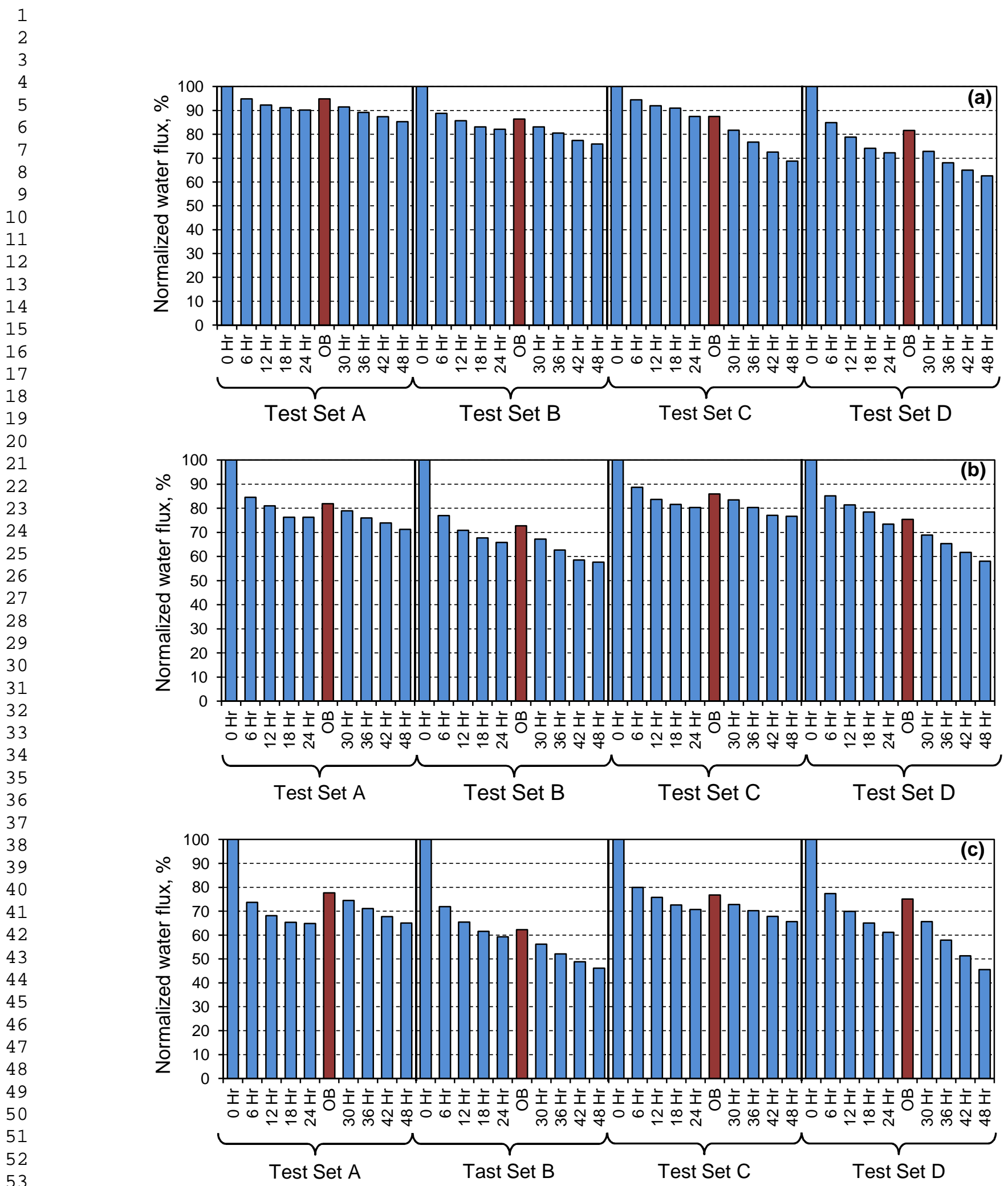

Fig. 2. Normalized water flux for the (a) CTA, (b) TFC1, and (c) TFC2 membrane fouling tests. Test sets indicate intervals of different operating conditions during the bench-scale study and are defined in Table 2. Water flux was normalized to the initial flux for each test set, independently. Osmotic backwashing (OB) was conducted after 24 hours of membrane fouling during each test set. The average initial water flux for each membrane was $4.3 \pm 0.3 \mathrm{LMH}$ for CTA, $7.4 \pm 1.4 \mathrm{LMH}$ for TFC1, and $7.2 \pm 0.7 \mathrm{LMH}$ for TFC2. 


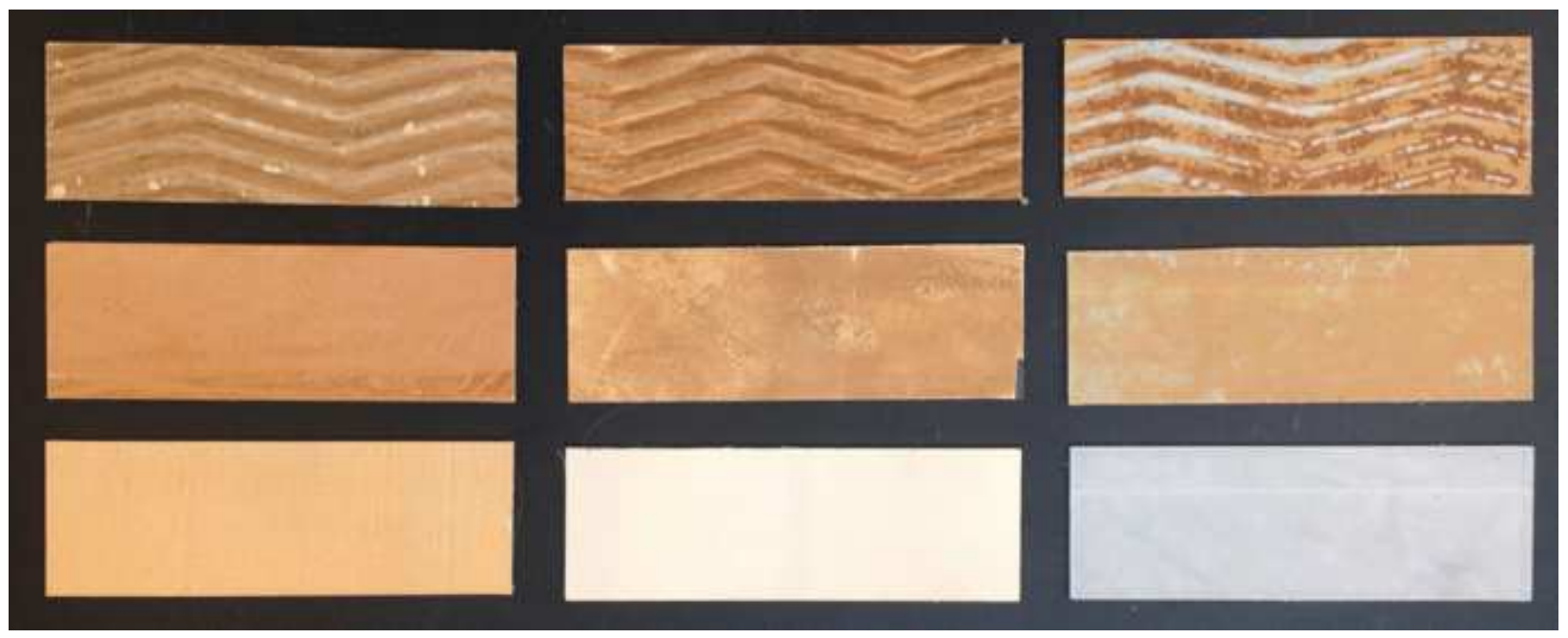

Fig. 3. Images of virgin and fouled CTA, TFC1, and TFC2 membrane samples. Fouled coupons are from membranes used under test set $A$ and test set $B$ conditions.

Results from the current study suggest that during treatment of produced water with spiral wound modules, FO membrane fouling could be exacerbated by the presence of feed spacers. This raises questions regarding use of spiral wound $\mathrm{FO}$ elements for treatment of complex feed streams with minimal pretreatment [2], especially in light of results from a recent study where activated sludge was treated with plate-and-frame FO modules for over 120 days with no cleaning and minimal fouling [58]. In spiral wound FO modules, membrane performance can be increased and fouling minimized by increasing cross-flow velocity; however, this can increase the energy demand of the FO system significantly. For example, in a recent pilot scale study in the Haynesville Basin [2] the energy demand of the FO system was approximately $15 \mathrm{kWh} / \mathrm{m}^{3}$ when operated under conditions similar to this study (test sets $C$ and $D$ ). This value exceeds the energy demand of traditional seawater reverse osmosis by nearly 4 times. It is important to note that this energy demand is likely to decrease substantially (from $15 \mathrm{kWh} / \mathrm{m}^{3}$ to 5 $\mathrm{kWh} / \mathrm{m}^{3}$ ) if the feed spacer thickness is minimized (100 mil to 30 mil) due to significantly lower pumping requirements to maintain adequate cross-flow velocity in the membrane module; however, feed pretreatment is required in O\&G applications if feed spacer thickness is reduced. At $\$ 0.10 \mathrm{kWh}, 15$ $\mathrm{kWh} / \mathrm{m}^{3}$ translates to $\$ 0.24$ cost of energy for treatment of one barrel (42 US gallons $=159 \mathrm{~L}$ ) of produced water. This is a very low O\&M (energy is $>75 \%$ of O\&M) for treatment of produced water, especially given the high quality permeate that is generated with no pretreatment of the feed water (See Section 3.4).

\subsection{Contaminant rejection by FO membranes}

\subsubsection{Rejection of inorganic solutes}

The rejection of dissolved inorganic ions during test set $A$ and test set $D$ for the three membranes is shown in Fig. 4. These results represent solute rejection during experiments that exhibited the least (A) and most (D) membrane fouling and flux decline. Greater than $94 \%$ rejection of cations by the CTA membrane was observed in both test sets (Fig. 4a); the concentrations of feed anions (i.e., bromide, 
fluoride, sulfate, nitrate, phosphate) in the DS were below detection limit throughout the study. Comparable cation rejection under the different testing conditions indicates that the diffusion of each analyte was largely independent of valence, molecular weight, and hydration radius. The rejection of divalent cations by CTA was slightly lower than that observed in previous studies [23, 27, 59]. This is likely due to cake enhanced CP resulting from the complexation of divalent cations with DOC at the membrane surface [47]. ATR-FTIR transmittance measurements of the fouled membrane surfaces indicated an overwhelming presence of calcium carbonate with traces of oil residues $(>93.5 \%$ compound match to Omnic software library (Fig. S2 in the Supporting Materials). The zeta potential of each fouled membrane was also $10 \mathrm{mV}$ to $20 \mathrm{mV}$ more negative than virgin samples (at $\mathrm{pH}$ ), further supporting the likelihood of cake enhanced CP resulting from divalent cation-DOC complexation at the membrane surface (Fig. S2 in the Supporting Materials). Similar findings were presented by Childress et al. [29], while investigating the impacts of humic acid in the presence of divalent cations on membrane zeta potential. Membrane scaling was also probable due to high carbonate concentrations in the feed, which would be exacerbated near the membrane surface. Cake enhanced CP and membrane scaling increased the solute concentration at the membrane boundary layer and thus the driving force for diffusive-based transport of ions into the DS. Higher ion transport (lower rejection) was measured during test set $D$, which was attributed to lower water recovery (compared to test set A) and severe cake enhanced CP due to cake layer compaction at high TMP.
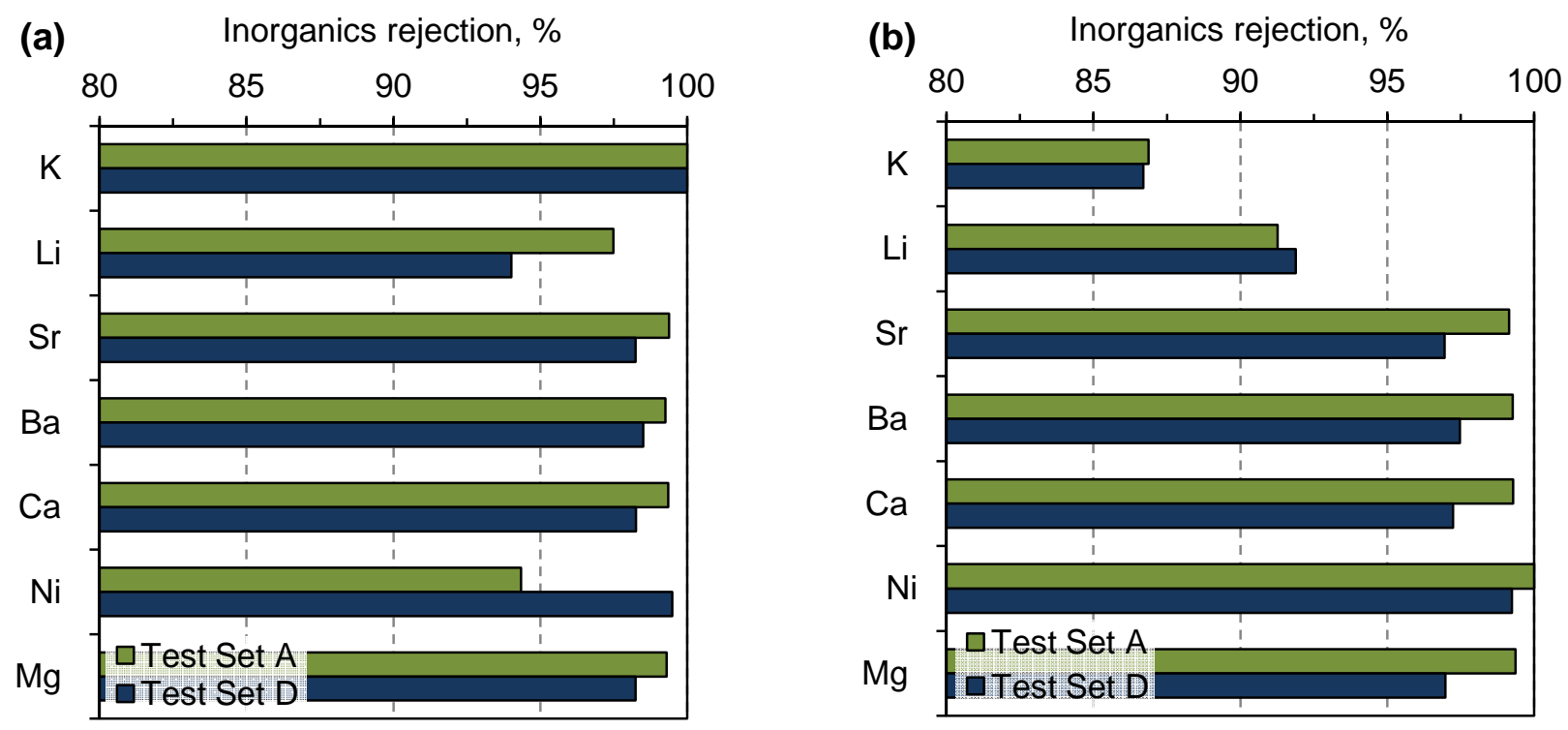


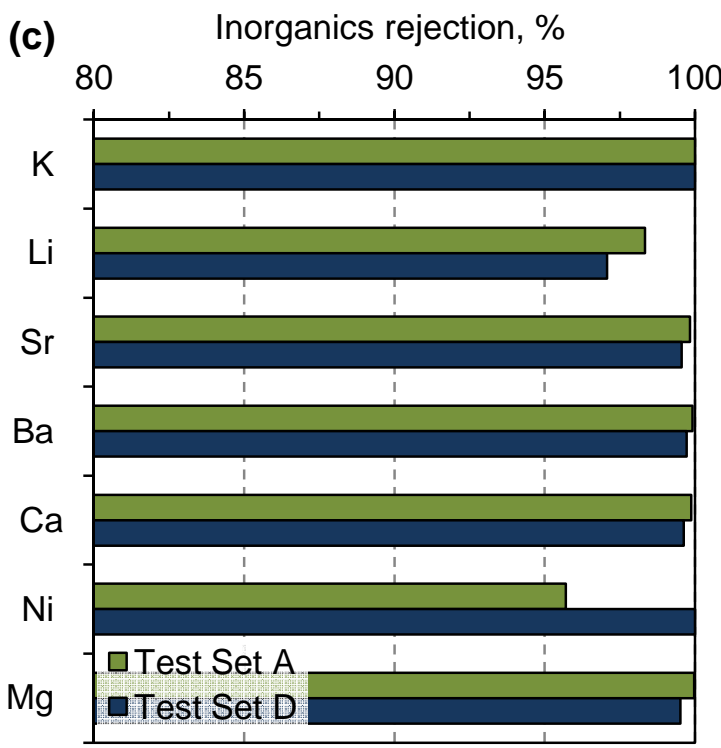

Fig. 4. Rejection of dissolved ions by the (a) CTA, (b) TFC1, and (c) TFC2 membranes during test set A and D. Operating conditions for each test set are shown in Table 2.

Ion rejection by the polyamide TFC1 membrane (Fig. 4b) was lower than that of the CTA membrane. Monovalent cation rejection increased with molecular weight and hydration radius. Divalent cation rejection was greater than $95 \%$ and comparable for all solutes regardless of valence and molecular weight. Similar to CTA, rejection of divalent cations was lower than anticipated due to cake enhanced concentration polarization and membrane scaling. Lower cation rejection by TFC1 was also expected due to electrostatic attraction to the functionalized polymer surface, regardless of ionic strength [53]. Contrary to the results observed with TFC1, cation rejection measured for TFC2 (Fig. 4c) was the highest throughout the study despite severe membrane fouling; at least $96 \%$ rejection of cations was measured in both test sets. While the physiochemical properties of TFC2 are similar to that of CTA (Table 2), the membrane zeta potential of TFC2 is near neutral and might result in lower electrostatic attraction of feed cations to the membrane surface and minimize CP. Similar to CTA, cation rejection by both polyamide TFC membranes was lower during test set $D$ due to lower water recovery (compared to test set $A$ ) and severe cake enhanced concentration polarization.

\subsubsection{Rejection of dissolved organic carbon and total nitrogen}

The rejection of $\mathrm{DOC}$ and total nitrogen (TN) by the three membranes during test sets $A$ and $D$ are shown in Fig. 5. The rejection of DOC was in agreement with trends observed with inorganic ion rejection. TFC2 exhibited the highest rejection of DOC, followed by CTA and then TFC1. The lowest DOC rejection observed throughout the study was $93 \%$ by TFC1, while the highest rejection was nearly $98 \%$ for TFC2. DOC rejection was similar for all membranes tested regardless of operating conditions; however, slightly higher DOC rejection was measured (Fig. 5a) when increased membrane fouling was observed (Fig. 1). 
These results suggest that cake layer formation on the membrane surface effectively shields the active layer and increases the sorption capacity for additional contaminants, while reducing the mass transport capacity. Increased DOC rejection also shifts the membrane zeta potential more negative [29], increasing the electrostatic attraction of cations near the membrane surface and thereby increasing the concentration gradient across the membrane boundary layer. Therefore, lower cation rejection due to $\mathrm{CP}$ (Fig. 4) is exacerbated by increased electrostatic attraction and correlates well with increased DOC concentration at the membrane surface.

All membranes in the study poorly rejected TN present in the produced water, and no obvious correlation with membrane fouling was observed. TN rejection ranged from $85 \%$ to $89 \%$ for CTA and from $59 \%$ to $67 \%$ for TFC1. The performance of TFC2 was more consistent and TN rejection was approximately $84 \%$ during both test sets. Although the mass transport of TN could not be correlated with molecular weight and hydration radius, it appears that the order of TN rejection by each membrane was similar to that observed for inorganic ion rejection (CTA $\approx T F C 2>T F C 1)$.
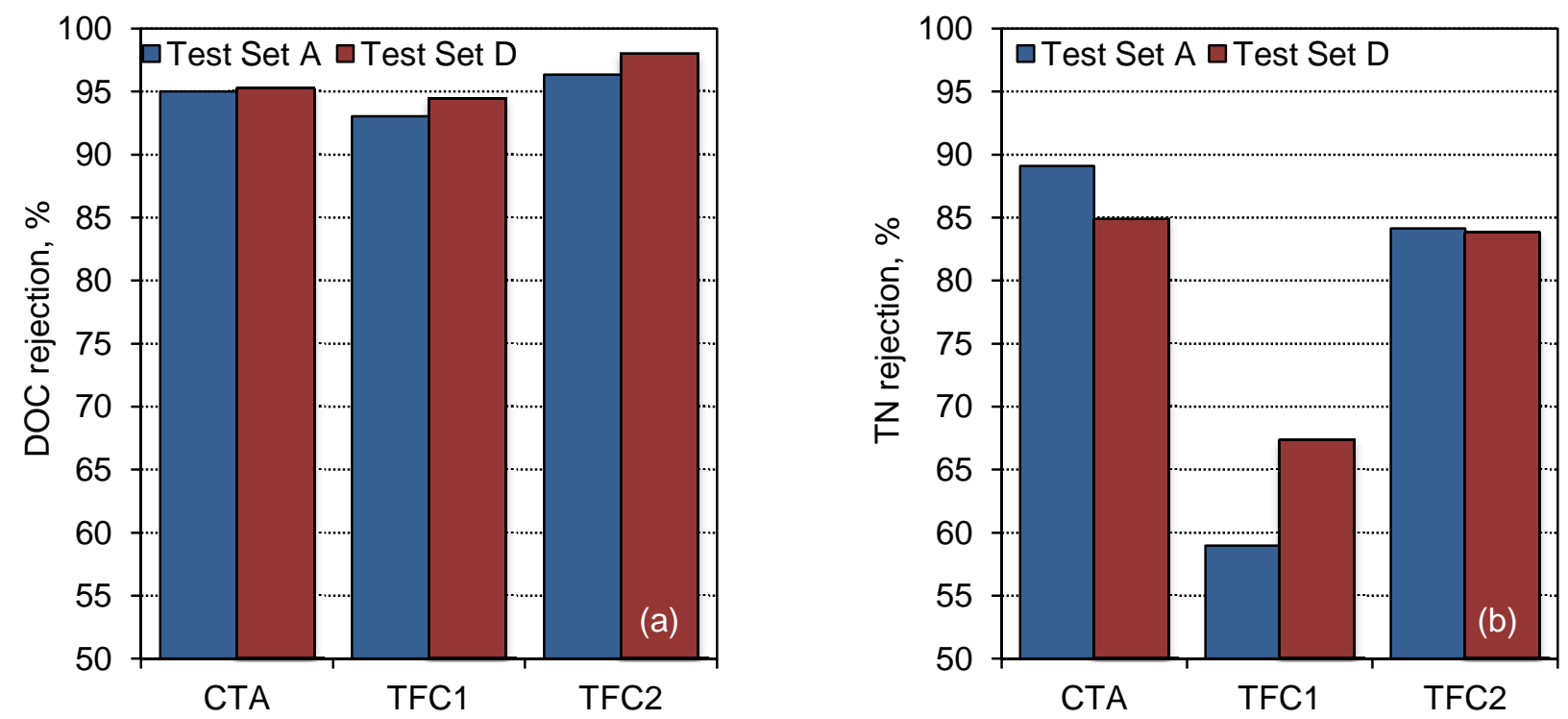

Fig. 5. Rejection of (a) dissolved organic carbon (DOC) and (b) total nitrogen by the CTA, TFC1, and TFC2 membranes during test sets A and D. Operating conditions for the test set are summarized in Table 2.

Fluorescence spectrophotometry was employed to qualitatively characterize the composition of dissolved organic compounds that diffused across the different polymeric membranes. Excitationemission (EEM) plots of the draw solutions from the end of test set $D$ are shown in Fig. 6. A list of peaks identified in this study and observed in previous publications is summarized in Table 4. No peaks were observed in the initial draw solution (not shown) and the system was operated at constant DS concentration. Therefore, the peaks shown in DS samples from the end of the experiment are due to the diffusion of organic compounds across the membrane and subsequent accumulation in the DS tank. 

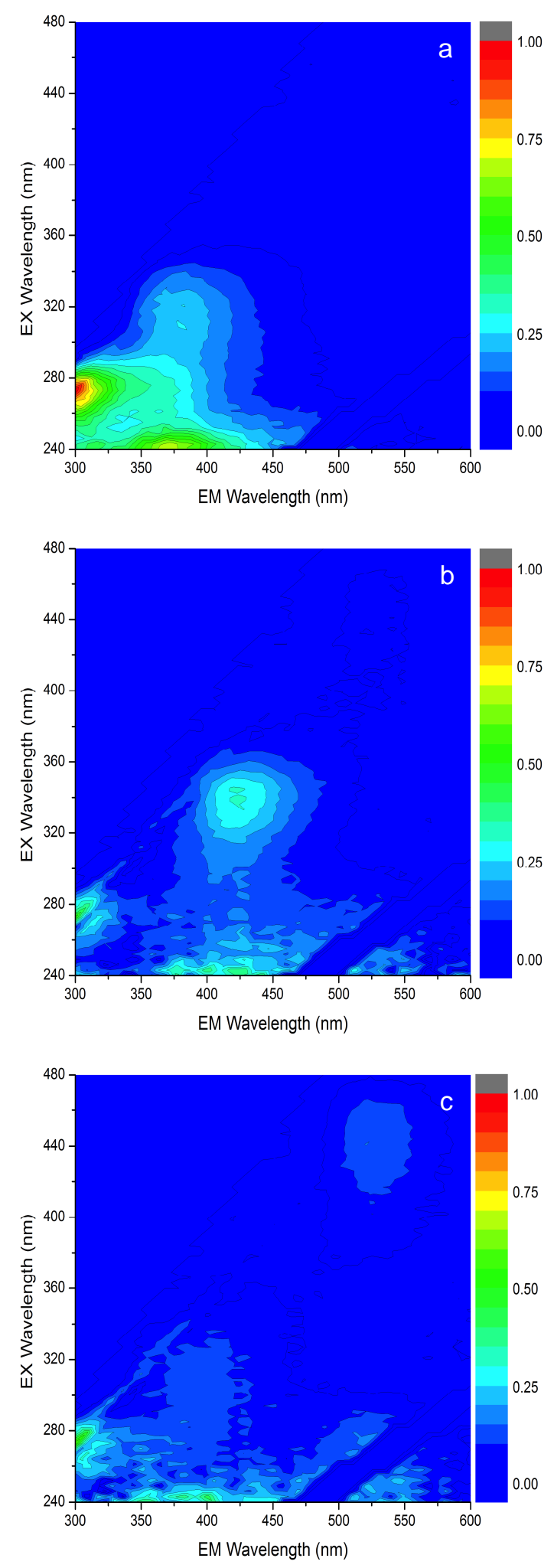

Fig. 6. Comparison of draw solution EEMs at the end of test set D for (a) CTA, (b) TFC1, and (c) TFC2. All EEMs intensities are normalized to a draw solution DOC concentration of $2.0 \mathrm{mg} / \mathrm{L}$. 
Marine humic-like organic compounds (Table 4) were present in the DS after experiments with the CTA membrane (Fig. 6a), but no fulvic-like organic compounds were identified. Visible humic-like and soil fulvic-like organic compounds were present in the TFC1 DS (Fig. 6b) and little influence of marine humiclike organic compounds was detected. The difference in organic composition between the CTA and TFC1 final DS indicates that preferential diffusion of different organic compounds might be a function of polymer chemistry and supports the similar observations reported for the rejection of TN (some of which is definitely organic nitrogen). Interestingly, the characteristics of the organic compounds detected in the TFC2 DS (Fig. 6c) were broad and similar to both the CTA and TFC1 membrane, despite its superior rejection. A broad peak indicative of marine humic-like and visible humic-like organic compounds was identified in addition to a soil fulvic-like organic peak. Fluorescence peaks shown in Fig. 6 are also similar to those of several common polycyclic aromatic hydrocarbons previously investigated by Ferretto et al. [60]; however, several of these peaks overlap with different organic compounds observed in previous studies [61-64]. While the EEMs obtained in our study support conclusions regarding the preferential diffusion of organic compounds based on membrane polymer chemistry, they also show that a key focal point in future studies must be the advancing of analytical capabilities for characterizing the DOC in produced water to better understand the preferential diffusion of organic compounds across different membranes.

Table 4. Previously identified spectra positions of the fluorescence maxima of dissolved organic matter and select PAHs

\begin{tabular}{lccc} 
Description & Emission Max $(\mathrm{nm})$ & Excitation Max $(\mathrm{nm})$ & Ref \\
\hline Marine humic-like & $370-410$ & $290-310$ & {$[63,64]$} \\
Visible humic-like & $420-460$ & $320-360$ & {$[63,64]$} \\
Soil fulvic acid-like & 521 & 455 & {$[63,64]$} \\
\hline Fluorene & 310 & 260 & {$[60]$} \\
Phenanthrene & 366 & 250 & {$[60]$} \\
Anthracene & 382 & 245 & {$[60]$} \\
& 402 & 245 & \\
Pyrene & 374 & 240 & {$[60]$} \\
& 392 & 240 & \\
\hline
\end{tabular}

\subsection{Effects of chemical cleaning on membrane performance}

The long term performance and effects of chemical cleaning of CTA and TFC2 are shown in Fig. 7. Each membrane was tested for 24 hrs with produced water feed and then chemically cleaned using EDTA or KL7330 for 30 min. After chemical cleaning, the membranes were tested for an additional 24 hrs with produced water feed to compare between the fouling propensity of virgin and chemically cleaned membranes; this process was repeated three times (total of $96 \mathrm{hrs}$ ). The water flux of each membrane is normalized to the initial water flux recorded at the beginning of the experiment. 

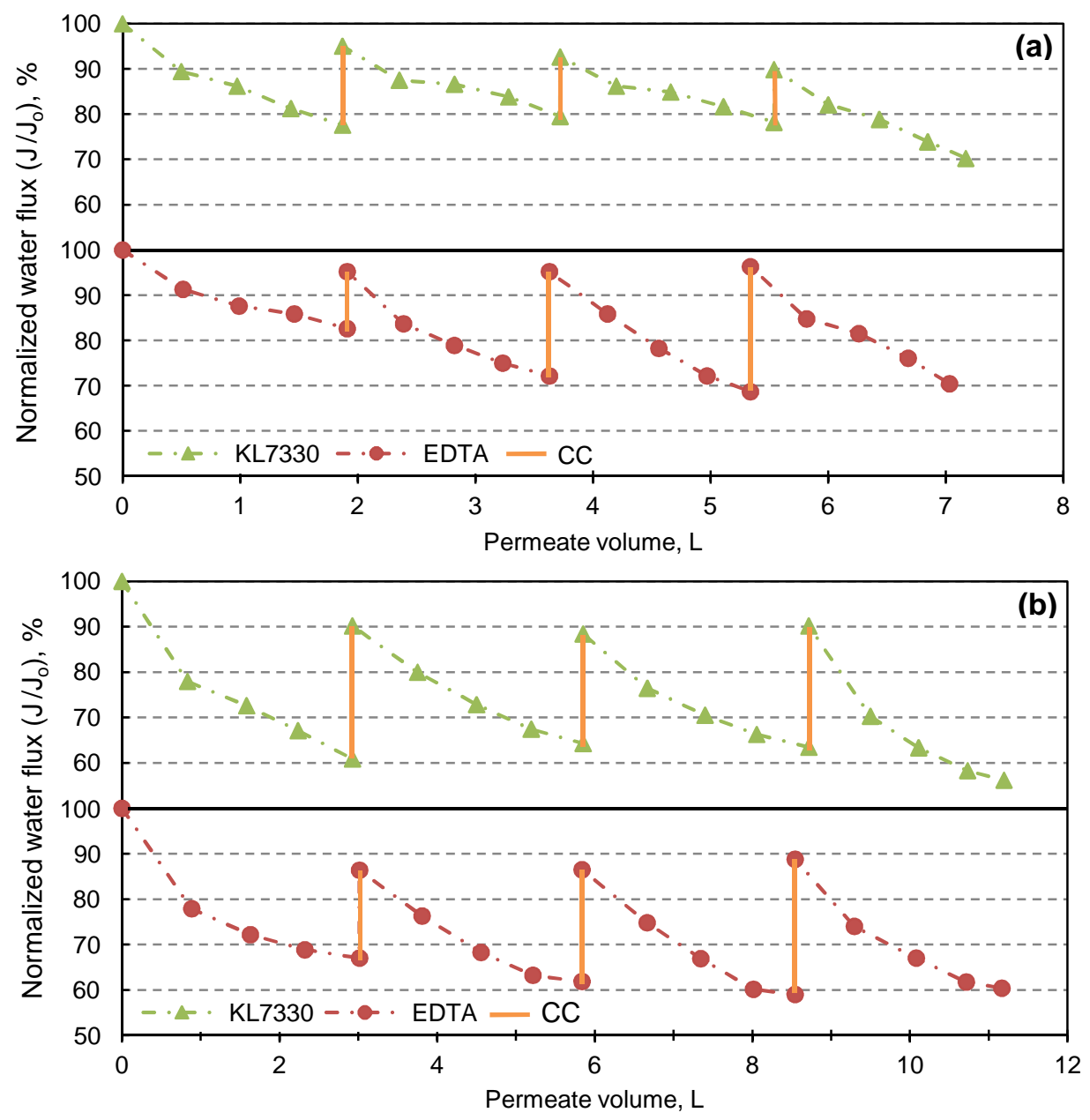

Fig. 7. Normalized water flux data for (a) the CTA membrane chemically cleaned with KL7330 and EDTA and (b) the TFC2 membrane chemically cleaned with KL7330 and EDTA. Fouling tests were conducted using experimental conditions outlined in test set $D$ (Table 2). Water flux was normalized to the initial flux for each experiment. Chemically cleaning (CC) was conducted for 30 minutes after every 24 hours of continuous membrane testing with produced water feed. The average initial water flux was $4.6 \pm 0.0 \mathrm{LMH}$ for the CTA and $8.6 \pm 0.1 \mathrm{LMH}$ for the TFC2.

In general, the normalized water flux data is similar to results shown for test set $D$ in Fig. 2. During the initial fouling of the virgin CTA membrane, the water flux declines exponentially, followed by a gradual transition into near linear flux decline. During the initial fouling of the virgin TFC2 membrane, the water flux declines exponentially throughout the first $24 \mathrm{hrs}$ of testing. Steady state water flux was never reached before each membrane was chemically cleaned. Water flux was consistently returned to near $90 \%$ of the initial flux (or greater) for the two membranes, resulting in significantly less irreversible fouling compared to osmotic backwashing cleaning. During subsequent fouling of each membrane, a similar decline in water flux was observed for each membrane, indicating that chemical cleaning effectively cleaned the membranes to near virgin conditions. Similar to results above (Fig. 1 and Fig. 2), the decline in water flux was greatest for the TFC2 membrane, despite effective chemical cleaning every 24 hrs. 
After chemical cleaning, water flux through CTA recovered by approximately $78 \%$ and $72 \%$ for the KL7330 and EDTA, respectively (Fig. 7a). The cleaning performance of EDTA remained nearly constant across all three cleaning events; however, the cleaning efficiency of KL7330 gradually declined and flux recovery was only $53 \%$ after the last cleaning event. Based on the above results and direct observation of the membrane surface, we infer that KL7330 is suitable for targeting the loosely bound organic foulants near the surface of the complex cake layer, but inefficient at addressing divalent-organic compound complexations and scaling at the CTA membrane interface. These findings are supported by the change in CTA membrane fouling during each subsequent fouling experiment. The exponential flux decline observed early in the experiments changed to near linear flux decline by the end of the study, indicating a gradual shift from fouling dominated by membrane-foulant interactions to foulant-foulant interactions. Furthermore, these findings are also supported by the consistent cleaning efficiency of EDTA, which specifically targets divalent-organic compound complexations in the cake layer. Water flux through the TFC2 membrane recovered by approximately $75 \%$ and $73 \%$ for the KL7330 and EDTA, respectively (Fig. $7 b)$. Despite the highest permeation drag force and filtration volume of the two membranes, the cleaning efficiency of TFC2 was comparable to CTA. Interestingly, even the cleaning performance of KL7330 for TFC2 remained consistent throughout the entire experiment and did not decline (compared to CTA). Therefore, it is likely that the extremely smooth surface of TFC2 enabled greater chemical cleaning efficiency of the membrane. These findings raise important questions regarding the economic tradeoffs between operating spiral wound FO systems with lower flux CTA membranes (resulting in lower fouling propensity) or with higher flux (and thus higher fouling rate) TFC membranes with potentially equal or superior cleaning properties to CTA.

After the final chemical cleaning event, each membrane coupon was removed for autopsy (ESEM coupled with EDS, ATR-FTIR, and zeta potential) to investigate membrane robustness and identify any possible changes to the membrane surface. Representative ESEM micrograph and EDS spectra are shown in Fig. 8 for TFC2 chemically cleaned with EDTA. In general, the chemical cleaning process successfully removed most foulants from the membrane surfaces that were not in contact with the chevron spacer (Figs. 8a and 8b). At points where the chevron spacer contacted the active layer, a significant cake layer was formed on the membrane surface. Neither chemical was effective at removing this irreversible fouling layer from the membrane-spacer interface, thus providing a nucleation site for subsequent foulant deposition and attachment. EDS spectra (Fig. 8c) taken from multiple areas of the cake layer revealed a significant presence of iron, barium, and calcium precipitates, which is consistent with the scaling tendencies predicted by OLI for this particular produced water. These findings were consisted for both membranes, regardless of chemical used. 

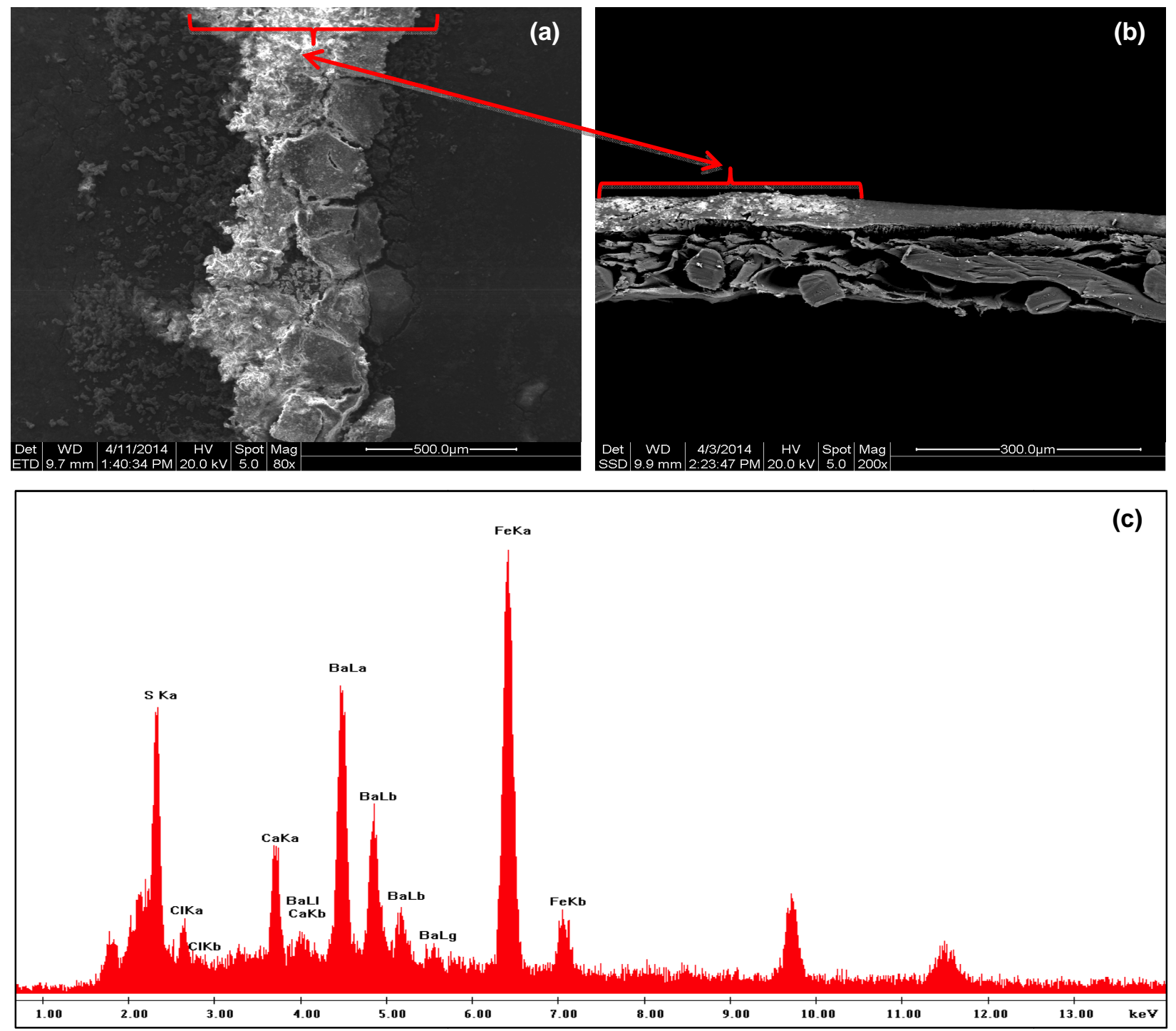

Fig. 8. ESEM micrograph of the TFC2 membrane (a) active layer and (b) cross section after fouling with produced water and subsequent chemical cleaning with EDTA. Irreversible organic fouling and inorganic scaling were observed on the membrane active layer, where the feed spacer contacts the membrane surface. (c) EDS spectrum of the fouling region on the membrane active layer indicates major ions present in the scaling layer.

ATR-FTIR transmittance spectra and zeta potential measurements are presented in Fig. 9 for both membranes. Virgin coupons were analyzed in addition to coupons fouled and chemically cleaned to identify possible changes to each FO membrane after extended exposure to produced water. The CTA membrane exhibited no change in ATR-FTIR transmittance spectra (Fig. 9a), indicating exceptional robustness and resilience to chemical change of the polymeric active layer after exposure to produced water. The zeta potential of CTA changed slightly from pH 4 to $\mathrm{pH} 8$ (Fig. 9b), suggesting a possible change to the membrane's electrokinetic properties; however, this slight change is likely due to the small concentration of negatively charged organic compounds irreversibly sorbed to the membrane surface. 
This phenomena was investigated by Childress et al. [29], who demonstrated the effect of organic compounds and divalent-organic compound complexations on membrane zeta potential.
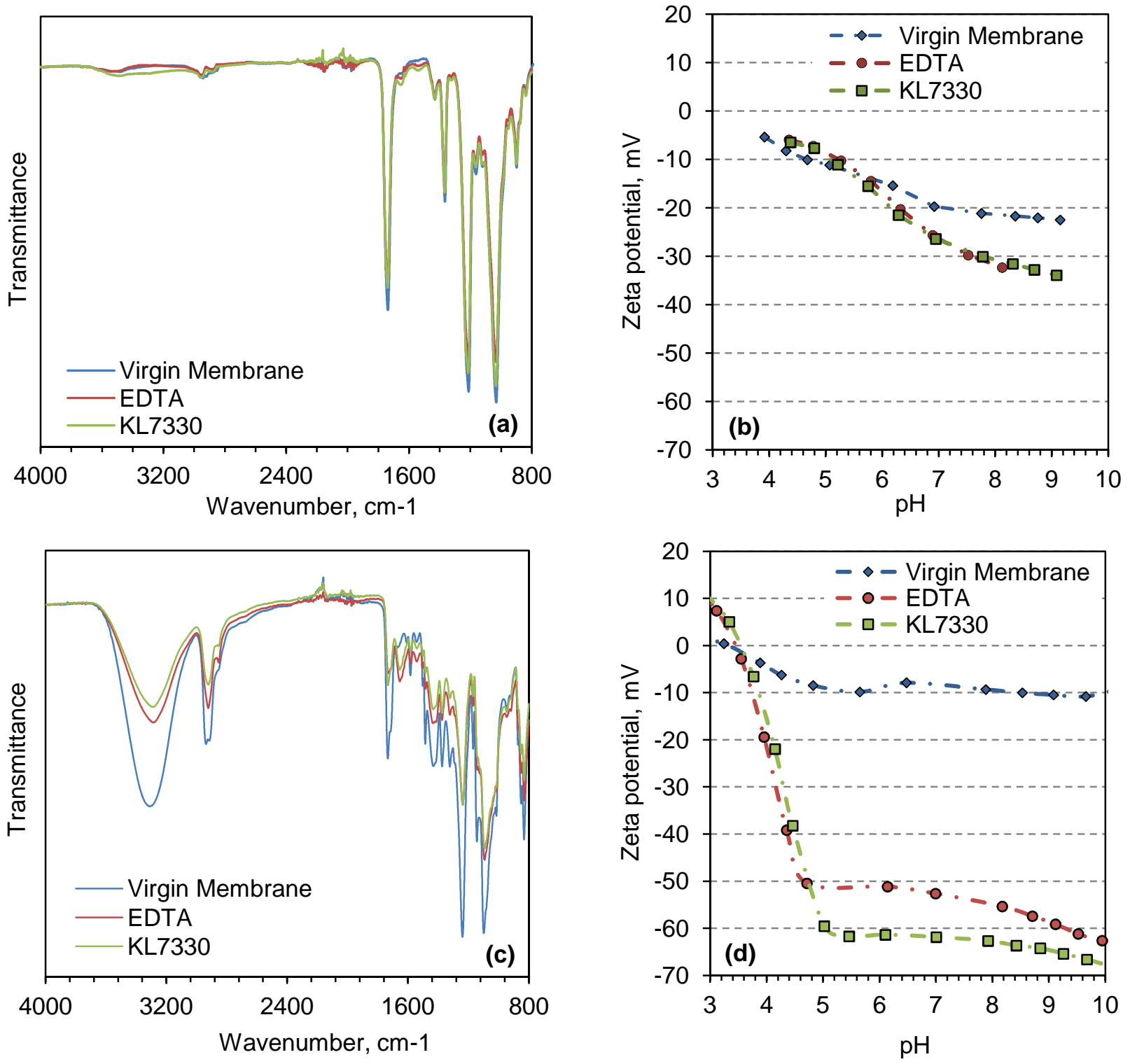

Fig. 9. ATR-FTIR transmittance spectra for (a) CTA and (c) TFC2. Each graph shows the transmittance spectrum for samples analyzed from a virgin membrane and fouled membranes chemically cleaned with EDTA and KL7330. Zeta potentials of virgin and chemically cleaned (b) CTA and (d) TFC2 membrane samples.

Contrary to CTA, the TFC2 membrane exhibited substantial shifts in ATR-FTIR transmittance spectra (Fig. 9b). This indicates that the TFC2 polymer chemistry might be susceptible to chemical interaction with contaminants in the produced water. These findings might be supported by the significant decrease in zeta potential measurements of TFC2 after the majority of the fouling layer was chemically removed from the active layer. The zeta potential of the chemically cleaned TFC2 membrane was approximately 50 
$\mathrm{mV}$ more negative than virgin samples (Fig. 9d) and even $25 \mathrm{mV}$ more negative than the fouled membrane ( -30 mV at pH 7 (data not shown)). Furthermore, the zeta potential of the chemically cleaned TFC2 membrane closely resembled the ionization curve of an amphoteric surface from $\mathrm{pH} 3$ to $\mathrm{pH} 10$ (Fig. 9d). It is unlikely that such changes are induced by the chemical cleaning process due to similar changes in membrane physiochemical properties, regardless of chemical employed during membrane cleaning.

\section{Conclusions}

Results from the current study suggest that during treatment of produced water with no pretreatment: (1) FO membrane fouling is dominated by initial water flux and permeation drag in the short term; (2) physiochemical surface properties might play a more important role during membrane cleaning, especially under optimized conditions (e.g., suitable chemical cleaner versus osmotic backwashing); (3) long-term membrane fouling is dominated by foulant-foulant interactions after the formation of a cake layer, regardless of membrane type; (4) long-term fouling might be mitigated with suitable chemical pretreatment with appropriately selected anti-scalants or anti-foulants; and (5) long-term FO system performance might be better controlled with optimized hydrodynamic conditions near the membrane surface (i.e., feed flow velocity, module design, membrane packing) and not by membrane selection. This is especially important given the recent surge of interest in TFC membranes for treatment of complex feed streams with FO.

In general, the FO membranes demonstrated very high rejection of dissolved ions and organic compounds. While results from this study suggest that long-term rejection of feed stream contaminants might decline in the presence of a complex cake-layer at the membrane surface due to concentrative CP, the DS is of suitable quality for local reuse in subsequent hydraulic fracturing operations and for downstream desalination processes like RO. Further research and more well defined analytical techniques are needed to better understand, and accurately quantify the composition of dissolved organic compounds and nitrogen containing species that do permeate through the FO membranes into the DS. This is especially true given the complex nature and high TDS of most O\&G production wastewaters, in addition to the highly concentrated DS streams that must be employed. Furthermore, accurate contaminant quantification is also of the utmost importance in cases where downstream desalination process might be employed and contaminants could become concentrated in the closed loop DS stream over time.

The chemical cleaning efficiency of EDTA was highest throughout the study and was likely due to its high $\mathrm{pH}$ when mixed in solution and its chelating properties. Interestingly, the chemical cleaning efficiency of the TFC2 membrane remained consistent throughout the study and did not decline compared to CTA membrane. It is likely that the very smooth surface of TFC2 enabled higher chemical cleaning efficiency of the membrane, raising important questions regarding the potential economic tradeoffs between operating FO systems with lower flux CTA membranes (resulting in lower fouling propensity) or with 
higher flux (and thus higher fouling rate) TFC membranes with potentially equal or superior cleaning properties to CTA. This is despite the fact that the contribution of the physiochemical surface properties of each membrane to its fouling propensity (compared to permeation drag) remains unclear given the complex nature of the feed stream.

\section{Acknowledgements}

Support of this investigation was provided by DOE/RPSEA project 10122-39. The authors would like to thank Hydration Technology Innovations for providing membranes for the study. Special thanks to Dr. Jonathan Brant, Satish Muthu, and Luke Ruff (University of Wyoming) for their technical advice and assistance with AFM measurements. The authors would also like to thank Estefani Bustos for her assistance with laboratory analyses and sample preparation. The CSM Undergraduate Research Fellowship Program is acknowledged for their financial support of Nohemi Almaraz during this investigation.

\section{References}

[1] K.B. Gregory, R.D. Vidic, D.A. Dzombak, Water management challenges associated with the production of shale gas by hydraulic fracturing, Elements 7.3 (2011) 181-186.

[2] B.D. Coday, P. Xu, E.G. Beaudry, J. Herron, K. Lampi, N.T. Hancock, T.Y. Cath, The sweet spot of forward osmosis: Treatment of produced water, drilling wastewater, and other complex and difficult liquid streams, Desalination 333 (2014) 23-35.

[3] E. Barbot, N.S. Vidic, K.B. Gregory, R.D. Vidic, Spatial and temporal correlation of water quality parameters of produced waters from devonian-age shale following hydraulic fracturing, Environmental science \& technology 47 (2013) 2562-2569.

[4] M.E. Blauch, R.R. Myers, T. Moore, B.A. Lipinski, N.A. Houston, Marcellus shale post-frac flowback waters-Where is all the salt coming from and what are the implications?, SPE Eastern Regional Meeting, Charleston, WV, 2009.

[5] L.O. Haluszczak, A.W. Rose, L.R. Kump, Geochemical evaluation of flowback brine from Marcellus gas wells in Pennsylvania, USA, Applied Geochemistry 28 (2013) 55-61.

[6] B.D. Lutz, A.N. Lewis, M.W. Doyle, Generation, transport, and disposal of wastewater associated with Marcellus Shale gas development, Water Resources Research 49 (2013) 647-656.

[7] J.-P. Nicot, B.R. Scanlon, R.C. Reedy, R.A. Costley, Source and fate of hydraulic fracturing water in the Barnett shale: A historical perspective, Environmental science \& technology 48 (2014) 2464-2471.

[8] A. Vengosh, R.B. Jackson, N. Warner, T.H. Darrah, A. Kondash, A critical review of the risks to water resources from unconventional shale gas development and hydraulic fracturing in the United States, Environmental science \& technology 48 (2014) 8334-8348.

[9] M.S. Mauter, V.R. Palmer, Expert elicitation of trends in Marcellus oil and gas wastewater management, Journal of Environmental Engineering 140 (2014) 
[10] M.E. Blauch, Developing effective and environmentally suitable fracturing fluids using hydraulic fracturing flowback waters, SPE Unconventional Gas Conference, Pittsburgh, PA, 2010.

[11] S. Rassenfoss, From flowback to fracturing: Water recycling grows in the Marcellus Shale, Journal of Petroleum Technology 63 (2011) 48-51.

[12] M. Zoback, S. Kitasei, B. Copithorne, Addressing the environmental risks from shale gas development, Worldwatch Institute, 2010.

[13] S. Kakadjian, J. Thompson, R. Torres, S. Trabelsi, F. Zamora, Y.A. Hamlat, Stable fracturing fluids from produced water, SPE Kuwait Oil and Gas Show and Conference, Mishref, Kuwait, 2013.

[14] S. Ashkan Haghshenas, H.A. Nasr-El-Din, Effect of dissolved solids on reuse of produced water and proppant handling in hydraulic fracturing jobs in tight sand gas reservoirs, SPE Hydraulic Fracturing Technology Conference, The Woodlands, TX, 2014.

[15] A. Haghshenas, H.A. Nasr-El-Din, Effect of dissolved solids on reuse of produced water at high temperature in hydraulic fracturing jobs, Journal of Natural Gas Science and Engineering 21 (2014) 316-325.

[16] R. LeBas, P. Lord, D. Luna, T. Shahan, Development and use of high-TDS recycled produced water for crosslinked-gel-based hydraulic fracturing, SPE Hydraulic Fracturing Technology Conference, The Woodlands, TX, 2013.

[17] T.Y. Cath, A.E. Childress, M. Elimelech, Forward osmosis: Principles, applications, and recent developments, Journal of Membrane Science 281 (2006) 70-87.

[18] D.L. Shaffer, L.H. Arias Chavez, M. Ben-Sasson, S. Romero-Vargas Castrillón, N.Y. Yip, M. Elimelech, Desalination and reuse of high-salinity shale gas produced water: drivers, technologies, and future directions, Environmental Science \& Technology 47 (2013) 9569-9583.

[19] T. Yun, J.-W. Koo, J. Sohn, S. Lee, Pressure assisted forward osmosis for shale gas wastewater treatment, Desalination and Water Treatment ahead-of-print (2014) 1-9.

[20] R.L. McGinnis, N.T. Hancock, M.S. Nowosielski-Slepowron, G.D. McGurgan, Pilot demonstration of the $\mathrm{NH}<$ sub $>3</$ sub $>/ C O<$ sub $>2</$ sub $>$ forward osmosis desalination process on high salinity brines, Desalination 312 (2013) 67-74.

[21] X.-M. Li, B. Zhao, Z. Wang, M. Xie, J. Song, L. Nghiem, T. He, C. Yang, C. Li, G. Chen, Water reclamation from shale gas drilling flow-back fluid using a novel forward osmosis-vacuum membrane distillation hybrid system, Water Science and Technology 69 (2014) 1036-1044.

[22] N.R. Hutchings, E.W. Appleton, R.A. McGinnis, Making high quality frac water out of oilfield waste, SPE Annual Technical Conference and Exhibition, Florence, Italy, 2010.

[23] K.L. Hickenbottom, N.T. Hancock, N.R. Hutchings, E.W. Appleton, E.G. Beaudry, P. Xu, T.Y. Cath, Forward osmosis treatment of drilling mud and fracturing wastewater from oil and gas operations, Desalination 312 (2013) 60-66.

[24] B.D. Coday, B.G. Yaffe, P. Xu, T.Y. Cath, Rejection of trace organic compounds by forward osmosis membranes: A literature review, Environmental Science \& Technology 48 (2014) 36123624.

[25] T.-S. Chung, S. Zhang, K.Y. Wang, J. Su, M.M. Ling, Forward osmosis processes: Yesterday, today and tomorrow, Desalination 287 (2012) 78-81. 
[26] K. Lutchmiah, A.R.D. Verliefde, K. Roest, L.C. Rietveld, E.R. Cornelissen, Forward osmosis for application in wastewater treatment: A review, Water Research 58 (2014) 179-197.

[27] B.D. Coday, D.M. Heil, P. Xu, T.Y. Cath, Effects of transmembrane hydraulic pressure on performance of forward osmosis membranes, Environmental Science \& Technology 47 (2013) 2386-2393.

[28] A. Tiraferri, N.Y. Yip, A.P. Straub, S. Romero-Vargas Castrillon, M. Elimelech, A method for the simultaneous determination of transport and structural parameters of forward osmosis membranes, Journal of Membrane Science 444 (2013) 523-538.

[29] A.E. Childress, M. Elimelech, Effect of solution chemistry on the surface charge of polymeric reverse osmosis and nanofiltration membranes, Journal of Membrane Science 119 (1996) 253268.

[30] M. Elimelech, W.H. Chen, J.J. Waypa, Measuring the zeta (electrokinetic) potential of reverse osmosis membranes by a streaming potential analyzer, Desalination 95 (1994) 269-286.

[31] J.A. Brant, A.E. Childress, Assessing short-range membrane-colloid interactions using surface energetics, Journal of Membrane Science 203 (2002) 257-273.

[32] G. Hurwitz, G.R. Guillen, E. Hoek, Probing polyamide membrane surface charge, zeta potential, wettability, and hydrophilicity with contact angle measurements, Journal of Membrane Science 349 (2010) 349-357.

[33] L. Gourley, M. Britten, S. Gauthier, Y. Pouliot, Characterization of adsorptive fouling on ultrafiltration membranes by peptides mixtures using contact angle measurements, Journal of Membrane Science 97 (1994) 283-289.

[34] C. Bouchard, J. Jolicoeur, P. Kouadio, M. Britten, Study of humic acid adsorption on nanofiltration membranes by contact angle measurements, The Canadian Journal of Chemical Engineering 75 (1997) 339-345.

[35] C. Van Oss, Acid-base interfacial interactions in aqueous media, Colloids and Surfaces A: Physicochemical and Engineering Aspects 78 (1993) 1-49.

[36] C.J. van Oss, Development and applications of the interfacial tension between water and organic or biological surfaces, Colloids and surfaces B: Biointerfaces 54 (2007) 2-9.

[37] N. Avraham, C. Dosoretz, R. Semiat, Osmotic backwash process in RO membranes, Desalination 199 (2006) 387-389.

[38] K. Spiegler, J. Macleish, Molecular (osmotic and electro-osmotic) backwash of cellulose acetate hyperfiltration membranes, Journal of Membrane Science 8 (1981) 173-192.

[39] M. Park, J.H. Kim, Numerical analysis of spacer impacts on forward osmosis membrane process using concentration polarization index, Journal of Membrane Science 427 (2013) 10-20.

[40] J. Ren, J.R. McCutcheon, A new commercial thin film composite membrane for forward osmosis, Desalination 343 (2014) 187-193.

[41] N. El Shaari, M. Kedzierski, T. Gorham, Quantifying guar polymer recovery post hydraulic fracturing to determine the degree of fracture cleanup: A field study of the point of rocks formation california, SPE Western Regional Meeting, Irvine, CA, 2005. 
[42] R. Barati, J.T. Liang, A review of fracturing fluid systems used for hydraulic fracturing of oil and gas wells, Journal of Applied Polymer Science 131 (2014)

[43] S. Hong, M. Elimelech, Chemical and physical aspects of natural organic matter (NOM) fouling of nanofiltration membranes, Journal of Membrane Science 132 (1997) 159-181.

[44] C.Y. Tang, Q. She, W.C. Lay, R. Wang, A.G. Fane, Coupled effects of internal concentration polarization and fouling on flux behavior of forward osmosis membranes during humic acid filtration, Journal of Membrane Science 354 (2010) 123-133.

[45] Q. Li, Z. Xu, I. Pinnau, Fouling of reverse osmosis membranes by biopolymers in wastewater secondary effluent: Role of membrane surface properties and initial permeate flux, Journal of Membrane Science 290 (2007) 173-181.

[46] B. Mi, M. Elimelech, Chemical and physical aspects of organic fouling of forward osmosis membranes, Journal of Membrane Science 320 (2008) 292-302.

[47] V. Parida, H.Y. Ng, Forward osmosis organic fouling: Effects of organic loading, calcium and membrane orientation, Desalination 312 (2013) 88-98.

[48] Y. Gu, Y.-N. Wang, J. Wei, C.Y. Tang, Organic fouling of thin-film composite polyamide and cellulose triacetate forward osmosis membranes by oppositely charged macromolecules, Water Research 47 (2013) 1867-1874.

[49] A. Tiraferri, Y. Kang, E.P. Giannelis, M. Elimelech, Superhydrophilic thin-film composite forward osmosis membranes for organic fouling control: fouling behavior and antifouling mechanisms, Environmental science \& technology 46 (2012) 11135-11144.

[50] J. Mansouri, S. Harrisson, V. Chen, Strategies for controlling biofouling in membrane filtration systems: challenges and opportunities, Journal of Materials Chemistry 20 (2010) 4567-4586.

[51] E.M. Vrijenhoek, S. Hong, M. Elimelech, Influence of membrane surface properties on initial rate of colloidal fouling of reverse osmosis and nanofiltration membranes, Journal of Membrane Science 188 (2001) 115-128.

[52] M.M. Motsa, B.B. Mamba, A. D'Haese, E. Hoek, A.R. Verliefde, Organic fouling in forward osmosis membranes: The role of feed solution chemistry and membrane structural properties, Journal of Membrane Science 460 (2014) 99-109.

[53] B.D. Coday, T. Luxbacher, A.E. Childress, N. Almaraz, P. Xu, T.Y. Cath, Indirect determination of zeta potential at high ionic strength: Specific application to semipermeable polymeric membranes Journal of Membrane Science in press (2015) DOI: http://dx.doi.org/10.1016/i.memsci.2014.1012.1047.

[54] J.R. McCutcheon, M. Elimelech, Influence of concentrative and dilutive internal concentration polarization on flux behavior in forward osmosis, Journal of Membrane Science 284 (2006) 237247.

[55] E.M. Hoek, S. Bhattacharjee, M. Elimelech, Effect of membrane surface roughness on colloidmembrane DLVO interactions, Langmuir 19 (2003) 4836-4847.

[56] B. Mi, M. Elimelech, Organic fouling of forward osmosis membranes: Fouling reversibility and cleaning without chemical reagents, Journal of Membrane Science 348 (2010) 337-345.

[57] E.M. Hoek, M. Elimelech, Cake-enhanced concentration polarization: a new fouling mechanism for salt-rejecting membranes, Environmental Science \& Technology 37 (2003) 5581-5588. 
[58] R.W. Holloway, A.S. Wait, A.F. da Silva, J. Herron, M.D. Schutter, K. Lampi, T.Y. Cath, Longterm pilot scale investigation of novel hybrid ultrafiltration-osmotic membrane bioreactors, Desalination in press (2014) doi:10.1016/j.desal.2014.1005.1040.

[59] N.T. Hancock, T.Y. Cath, Solute coupled diffusion in osmotically driven membrane processes, Environmental Science \& Technology 43 (2009) 6769-6775.

[60] N. Ferretto, M. Tedetti, C. Guigue, S. Mounier, R. Redon, M. Goutx, Identification and quantification of known polycyclic aromatic hydrocarbons and pesticides in complex mixtures using fluorescence excitation-emission matrices and parallel factor analysis, Chemosphere 107 (2014) 344-353.

[61] N.T. Hancock, P. Xu, M.J. Roby, J.D. Gomez, T.Y. Cath, Towards direct potable reuse with forward osmosis: Technical assessment of long-term process performance at the pilot scale, Journal of Membrane Science 445 (2013) 34-46.

[62] K.G. Dahm, C.M. Van Straaten, J. Munakata-Marr, J.r.E. Drewes, Identifying well contamination through the use of 3-D fluorescence spectroscopy to classify coalbed methane produced water, Environmental science \& technology 47 (2012) 649-656.

[63] C.A. Stedmon, S. Markager, R. Bro, Tracing dissolved organic matter in aquatic environments using a new approach to fluorescence spectroscopy, Marine chemistry 82 (2003) 239-254.

[64] P.G. Coble, Characterization of marine and terrestrial DOM in seawater using excitation-emission matrix spectroscopy, Marine chemistry 51 (1996) 325-346. 